\title{
Tension-only ideal dissipative bracing for the seismic retrofit of precast industrial buildings
}

\author{
Bruno Dal Lago $^{1}$ (D) Muhammad Naveed ${ }^{2} \cdot$ Marco Lamperti Tornaghi $^{3}$
}

Received: 29 December 2020 / Accepted: 18 May 2021 / Published online: 7 June 2021

(c) The Author(s) 2021

\begin{abstract}
New precast frame industrial structures are seismically designed according to reliable modern criteria. However, most of the existing built stock hosting many workers and both regular and strategic industrial activities was designed and detailed neglecting the earthquake load or according to outdated seismic design criteria and regulations. Its seismic retrofit is a main challenge for the Engineering Community and a critical objective for institutional and private bodies. Among the envisaged solutions, the introduction of dissipative braces appears to be promising, although mostly inapplicable for these buildings, due to the brace lengths required by their typical large dimensions and the related proportioning against buckling. In this paper, an innovative seismic retrofitting technique based on monolateral dissipative bracing is investigated. The device proposed in this paper, yet in phase of preliminary design and testing, dissipates energy through friction in tension only while freely deforming in compression, which makes the issue related to compressive buckling irrelevant. A numerical analysis is carried out to investigate the efficiency of the proposed device in seismic retrofitting of precast industrial frame buildings with the aim to explore its feasibility and to better orient the definition of the slip threshold load range and the future development of the physical device. The simplified Capacity Spectrum Method (CSM) is employed for the global framing of the structural behaviour of the highly nonlinear retrofitted structures under seismic actions. A numerical tool is set to automatically apply the CSM based on the definition of few main parameters governing the seismic response of precast frame structures. The efficacy of the CSM is critically analysed through the comparison with the results of a set of nonlinear dynamic analyses. A smart simplified design process aimed at framing the most efficient threshold slip/yield load of the device given an existing structural configuration is presented with the application of the CSM through the identification of the most efficient performance indicator related to either displacement, shear force, equivalent dissipation of energy or a combination of them.
\end{abstract}

Keywords Seismic retrofit · Precast structures $\cdot$ Industrial buildings $\cdot$ Bracing system . Dissipative devices · Capacity spectrum

Bruno Dal Lago

bruno.dallago@uninsubria.it

Extended author information available on the last page of the article 


\section{Introduction}

Recent earthquakes occurred in Southern Europe highlighted a satisfactory behaviour of existing precast concrete industrial frame structures, whether they were originally conceived and designed for seismic strength. However, a poor performance leading to global column collapse of whole industrial facilities or local collapses involving loss of support of poorly connected horizontal elements, whether they were not conceived and designed considering the earthquake load, was observed (Toniolo and Colombo 2012; Bournas et al. 2013; Magliulo et al. 2014; Belleri et al. 2015a; Savoia et al. 2017; Batalha et al. 2019; Dal Lago 2021). In both conditions, the large drifts attained under the occurred strong earthquakes brought to issues of displacement compatibility with the "non-structural" claddings, often made with heavy precast concrete sandwich panels, leading to failure of their connections and to their collapse, as extensively reported in the above-cited literature.

The seismic retrofit of existing precast industrial frame buildings is currently a challenge and a critical objective to be tackled by the Engineering Community.

Several techniques for the seismic retrofitting/improvement of industrial precast RC buildings with structural deficiencies were discussed in literature (Martinelli and Mulas 2010; Belleri et al. 2015b, 2017; Dal Lago et al., 2018a; Pollini et al. 2018). Among them Valente (2013) and Sorace and Terenzi (2017) proposed to install dissipative devices in braces added to the precast frame structure. This type of intervention consists of a strong alteration of the original Lateral Force Resisting System (LFRS) typical of precast industrial buildings which, if properly designed and implemented, could lead to a significant reduction in the top displacement and, consequently, seismic damage.

Braces are widely used in the steel construction practice. The current typologies of braces may be classified as: (a) Tension-only or Mono-lateral (Fig. 1a); (b) Bi-lateral dissipative (Fig. 1b); Bi-lateral with moderate energy dissipation capacity (Fig. 1c).

Cost-effective Tension-only Braced Frames (ToBFs), using slender elements such as steel rods or flat/angle profiles (Fig. 1a), are the most widely employed bracing typology. These braces are unable to transmit load in compression, because of buckling (Filiatrault and Cherry 1987). Therefore, it is necessary to install couples of identical braces, each reacting in one direction only, which will inactivate once the loading movement reverses. These braces, as well as others, can be formed from simple diagonal-bracing (D-bracing) and cross-bracing (X-bracing), to shapes that allow multiple architectural options, such as Chevron-bracing (V-bracing) and K-bracing.

The lateral failure of a Braced Steel Frame (BSF) is attained, if correctly designed, after strong development of plastic strain and ductility of the tensioned braces. However, the asymmetric behaviour of bracing subjected to cyclic loads causes poor dissipative capacity. For this reason, the resulting hysteresis cycles show a pronounced pinching and a quick stiffness degradation (Popov et al. 1976; Tremblay 2002; Kanyilmaz 2017a, b). While no particular limitations are required for elastic ToBFs, which can also be very slender (ropes), other limitations must be observed according to Eurocode 8 to design moderately dissipative bracing, leading to bi-lateral braces.

The slenderness of bi-lateral braces shall be limited to achieve an overall elasto-plastic behaviour, therefore a certain dissipative contribution of the bracing in compression is required. Nevertheless, these systems are not able to guarantee a stable dissipative behaviour and they can only be used to achieve low-medium ductility (Perotti and Scarlassara 1991; Martinelli et al. 1996, 1998; Perotti et al. 1996; Broderick et al. 2008; Kanyilmaz 2018; Kanyilmaz et al. 2018). 


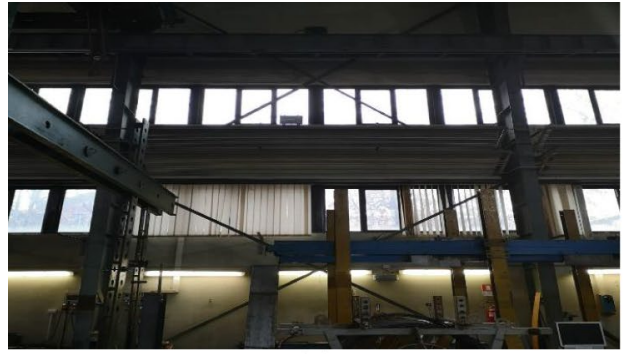

(a)

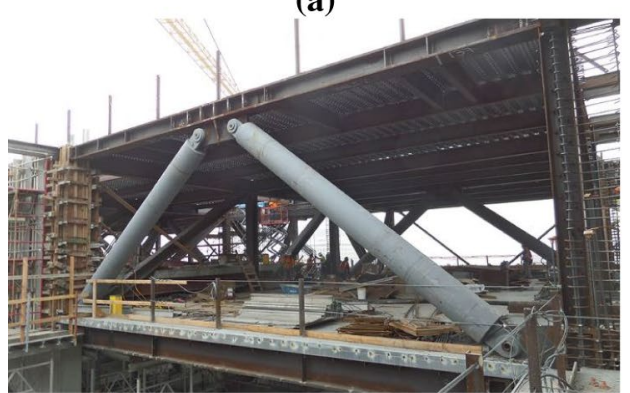

(b)

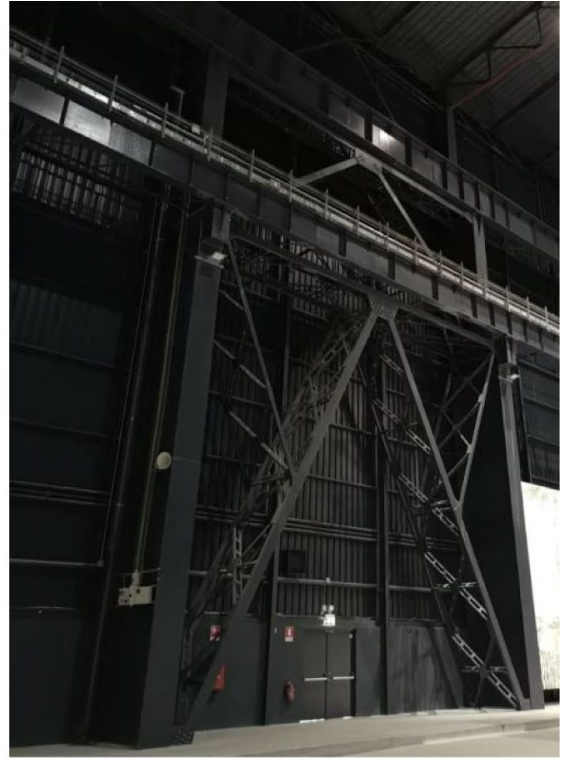

(c)

Fig. 1 Current typologies of bracing members: a tension-only traditional (moderate energy dissipation); b bi-lateral dissipative; and $\mathbf{c}$ bi-lateral traditional (moderate energy dissipation). Image $\mathbf{b}$ is courtesy of U.S. General Service Administration

Because of that, Moment Resisting Frames (MRFs) are favoured with higher force reduction (behaviour) factors for steel construction in areas with high seismic hazard because of their stable ductile behaviour under repeated reverse loading (Erochko et al. 2011), as reflected by current seismic codes such as Eurocode 8, ASCE/SEI 7, FEMA P440A and NBCC. Dual systems with braced-MRFs are considered in order to reduce the storey drift and to prevent non-structural damages, keeping a higher dissipative capacity (Aiken et al. 1993; Erochko et al. 2013).

As a further alternative, bi-lateral dissipative braces were introduced with the aim to develop ductility and energy dissipation in an almost equal manner in tension and compression. Although rarely employed yet, bi-lateral dissipative braces characterised by bulk and low cost-effective profiles required to restrain the brace from buckling were introduced in literature and practice. Buckling-Restrained Braces (BRB) were introduced following this concept (Tremblay et al. 2006; Fahnestock et al. 2007; Della Corte et al. 2015), where the typical devices dissipate energy for plasticisation of a metallic profile (often steel) subjected to bi-lateral axial strain while deforming inside a noncohesive external jacketing profile (Fig. 1b). These devices were recently proposed to be employed in precast concrete structures (Guerrero et al. 2018), although referring to office/residential smaller structures than the large industrial facilities typical of the European heritage. As a matter of fact, the current technology of BRBs allows to attain credible lengths of not more than about $8 \mathrm{~m}$, which makes the application of this technology to typical precast industrial structures hardly viable.

Since the seventies, several scholars proposed to preserve the primary structural elements, which bear the gravity-load, by the most severe earthquakes concentrating the 
inelastic deformation into specially designed and detailed parts (Kelly et al. 1972; Skinner et al. 1974).

Passive dampers presented during last decades to be used in earthquake engineering can be classified concerning: (a) material used (metallic-, shape-memory alloy-, viscous fluid-...), (b) employed physical principle (friction, ductility, tuned mass, magnetorheological...), or either (c) physical motion property they mainly react to (displacement, velocity, or acceleration). Details can be found in Soong and Dargush (1997), Martìnez-Rueda (2002), Symans et al. (2008), among others.

Among available passive solutions, a particular interest should be paid to Friction Damper Devices (FDDs); they are activated when a pre-set load threshold is reached, after which they slide, keeping an almost constant load-level and dissipate an amount of energy proportional to the displacement. In comparison to devices based on plasticisation of metals, they provide much larger initial stiffness, and thus they activate earlier, with a stable rectangular-shaped hysteresis, providing the largest amount of energy dissipation given a target displacement and a threshold load. Moreover, they often do not damage or only slightly damage even under severe motion and extensive friction activation (Grigorian et al. 1993; Dal Lago et al. 2017).

In addition, the number of available cycles is unequivocally higher than yielding-based devices (Dal Lago et al. 2018c), because fatigue and temperature do not affect friction, which is also poorly sensitive to the strain rate. Finally, the sliding threshold may be easily tuned according to the structural requirements. As effectively summarised in a well-known paper on the subject (Pall and Marsh 1982): «the motion of vibrating buildings is slowed down by braking rather than breaking».

Following this approach, it is natural to wonder whether the non-symmetrical behaviour of braces might be overcome by exploiting the properties of FDDs. Indeed, by installing a device with a determined slip threshold connected to a brace, it is possible to predetermine the maximum load transferred to the connected frame (with a safety margin) and avoid the yielding of brace at the same time; in this manner FDD acts as a mechanical-fuse, limiting the force exerted, and like a damper, controlling the displacement. The setting of the operating threshold may ensure that key design parameters are easily controlled since the conceptual design, without demanding calculation resources. In this manner, the capacity design becomes simpler and more effective, making the Performance Based Design easier (Kim et al. 2013).

The bigger hamper to the installation of such dampers in braces again arise from the combination of alternating tensile-compression behaviour; whether the tensile behaviour can be assimilated to an elastic-plastic element, the slender parts keep suffering for the compression brace buckling, as previously discussed.

Several solutions were proposed in literature and practice to overcome the issue of producing dissipation of energy with low-cost tensile bracing elements acting only in tension. Pall and Marsh (1982) proposed an enhanced X-bracing with a special device installed at the braces crossing. The mechanism is a four-bar linkage: the tension of one brace forces the device to slip, activating all four links which in turn force the joint of the other brace to slide simultaneously, which will reciprocate in the following half-cycle. In this way, the energy is dissipated during each half-cycle in both braces. In addition, at each cycle, the mechanism brings the connection back to initial position, ready to be reactivated in subsequent cycles. Besides introducing friction dissipation, this system has the undoubted advantage of correcting the non-symmetrical behaviour of the bracing. Also in this case, the application in precast structures becomes difficult, especially when long spans of beams or roof elements are present. 
The improvement of V-bracings proposed by Mualla and Belev (2002) is appealing for the coherent implementation of the form following function principle. Cables replace braces, whilst a single device improves the overall capacity of dissipating kinetic energy by friction and the same device uncouples the vertical displacement of the beam from the bracing. In this manner, braces are not affected by the beam deformation due to gravity load but, at the same time, the lateral load borne by the beam is transferred to columns base, like any common V-bracing.

Moreover, several attempts had been performed to integrate dampers with devices able to transmit tension only: Sumitomo Friction Damper (Aiken et al. 1993) and FrictionSpring Seismic Dampers (Filiatrault et al. 2000) are two leading examples.

Following the original Pall \& Marsh's idea, Fitzgerald et al. (1989) and Grigorian et al. (1993) later used slotted holes to avoid the brace buckling. These different devices have the same flag-shape response, which provides a remarkably lower specific energy dissipation with respect to the typical rectangular-shaped friction hysteresis.

Tamai and Takamatsu (2005) proposed to upgrade X-bracing by modifying gusset plates inserting a wedge-device, able to accommodate the brace shortening and avoid buckling, while the dissipation of energy remains entrusted to the yielding of tensile braces. The experiments showed a perfect elastic-plastic hysteresis and a good agreement with the designed strength and the foreseen energy absorption.

More recently, other scholars proposed to employ special mechanical devices, such as ratcheting bars based on steel plasticisation, in the field of structural engineering. Such devices are able to transmit a tensile axial load along one direction only, while they slide without resistance when they move in the reverse direction. Tamai and Takamatsu (2005) called them non-compression brace, also called from other authors Slack-Free Connection (SFC) (Mousavi et al. 2015), Tension-only Device (ToD) or Grip ' $n$ Grab (GnG) (Cook et al. 2018).

The analysed literature, presented so far, proposes the use of unilateral devices coupled to passive yield devices (Monir 2013) or directly exploiting the braces tensile yielding (Mousavi et al. 2015; Cook et al. 2018). Ratchet systems are characterised by an influence on the ratchet step, and by a limitation in the cumulated displacement since there is no "recovery" of the penetration length during use. Moreover, yielded devices should be replaced after mild/heavy engagement.

The above-cited issues may be overcome with the adoption of a Unidirectional Device coupled with a Friction Damper, leading to a Unidirectional Friction Damper Device (UFDD). In comparison with ratchet devices, the device would immediately be triggered by displacement, avoiding ratchet step influences, thus the system can be continuously re-armed without slack. The displacement cumulated by the device in use has no theoretical limit, given the hysteresis occurs within the maximum and minimum absolute displacements allowed by it. Moreover, by concentrating all the dissipation inside the friction dampers, it is not necessary to replace the damper and the bracing hardware after an earthquake.

The use of UFDDs to retrofit precast RC industrial buildings is proposed and analysed in the present paper. The conception of the physical friction device is introduced with reference to a primitive prototype, currently under testing and fine-tuning. Capacity Spectrum Method (CSM) is employed on simple frame models of precast structures. A numerical tool was set to automatically apply the CSM based on the definition of few parameters which govern the seismic response of precast frame structures: (a) height of column, (b) column width, (c) steel ratio, (d) grid size, (e) PGA, and (f) device threshold capacity. This simplified performance-oriented design method is straight forwarding and can immediately 
provide response of a highly nonlinear structure in terms of maximum displacement and maximum shear force.

The efficacy of the CSM is critically analysed through the comparison of the method outcomes against the results of a set of nonlinear dynamic analyses. Then, a wide parametric investigation is carried out considering the effects of each of the above-cited influencing parameters over the seismic performance of precast frame structures, identifying which are crucial. The performance curves obtained from parametric analysis will form the basis of designing criteria for the proposed dissipative device. Finally, a smart simplified design process aimed at framing the most efficient threshold slip/yield load of the device given an existing structural configuration is presented with the application of the CSM through the identification of the most efficient performance indicator related to either displacement, shear force, equivalent dissipation of energy or a combination of them.

\section{Unidirectional friction damper device and implementation into braces}

A concept prototype of UFDD is shown in Fig. 2. It consists of a wedged slider to be inserted into a mechanically calibrated (adjusted with high precision in diameter) steel tube. The slider is made by (1) a base diagonal-truncated cylinder with inner threaded hole connected to a threaded bar, and (2) a diagonal-truncated counter wedge cylinder with inner plain hole kept close to the base cylinder by a metallic spring acting against a classical nut of outer diameter lower than the cylinder diameter. When the slider is tensioned by the threaded bar, cylinder (1), which is screwed into the threaded bar, engages cylinder (2) with a wedging mechanism, increasing the pressure on the outer tube. Once the sliding threshold is reached, the device starts to slide inside the tube maintaining a friction force. On the contrary, when the slider is pushed cylinder (1) disengages from cylinder (2) by forming a gap, which is kept minimum at negligible load by the spring counteracting over the washer and the nut. The slider can be made out of steel (Fig. 2b) or brass (Fig. 2c), the latter being used for friction devices due to the stabilising effect on the hysteresis (Dal Lago et al. 2017).

When installed in slender braces, the UFDD modifies the typical behaviour of ToBFs shown in Fig. 3a into the behaviour shown in Fig. 3b.

The hysteretic behaviour of a typical non-dissipative ToBF is characterised by the following steps: (1) the high lateral displacement imposed to the structure $\delta$ ' causes the elastic-plastic elongation of the tensioned diagonal and the contemporary buckling of the compressed diagonal; ( 2 when back to zero displacement, the tensioned diagonal, elongated by the plastic deformation, buckles, while the compressed diagonal comes back to its original position; (3) when pushed to $-\delta^{\prime}$, also the previously undamaged diagonal undergoes plastic deformation, while the compressed diagonal buckles even more; (4) when back to zero displacement, both diagonals are loose and buckled; in successive cycles experiencing the same displacement history, their contribution to bracing and energy dissipation is fully jeopardised.

The installation of a UFDD unit into both braces modifies the hysteretic behaviour of the ToBF as follows: (1) the high lateral displacement imposed to the structure $\delta$ ' causes the sliding of the tensioned diagonal under the friction threshold load and the contemporary shortening by sliding with negligible load of the twin diagonal; (2) when back to zero displacement, the previously tensioned diagonal slides into its 
Fig. 2 Concept prototype of unidirectional friction damper device: a geometry and kinematics, $\mathbf{b}$ steel slider, $\mathbf{c}$ brass slider, $\mathbf{d}$ coupling of steel slider with tube

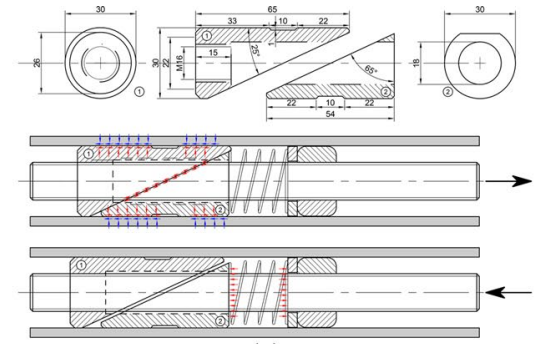

(a)

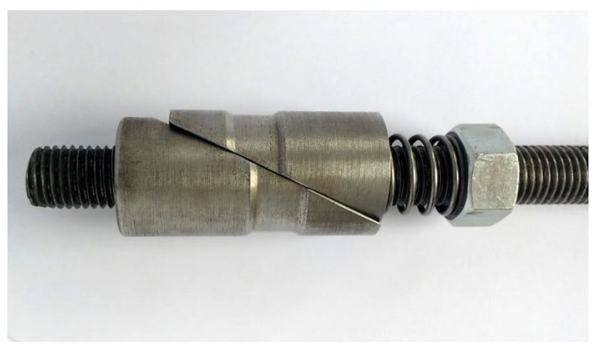

(b)

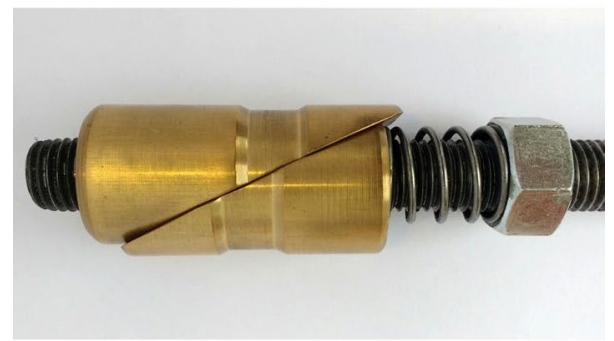

(c)

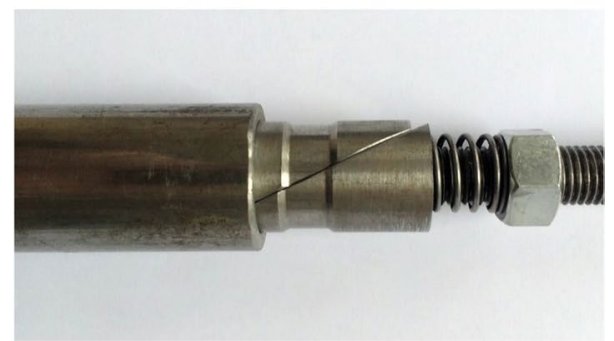

(d)

original position with negligible load, while the previously shortened diagonal activates friction sliding; (3) when pushed to $-\delta^{\prime}$, the same mechanism displays; (4) when back to zero displacement, both diagonals are in their original position; in successive cycles experiencing the same displacement history, their behaviour is similar to that of the first cycle apart from eventual friction losses (Dal Lago et al. 2017). 

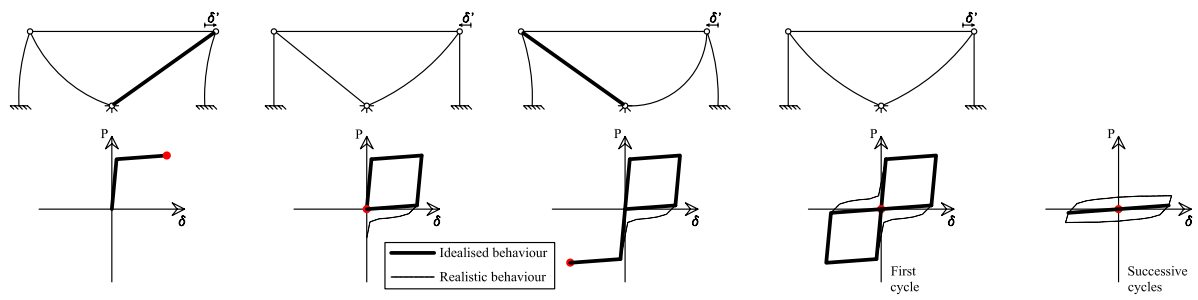

(a)
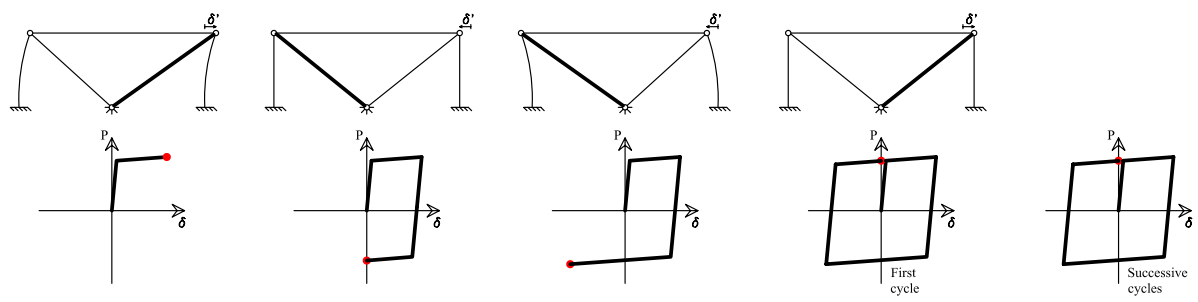

(b)

Fig. 3 Hysteretic behavior of tension-only braces: a traditional, and $\mathbf{b}$ dissipative

\section{Reference building}

The CSM can be used to estimate the inelastic response of a structure in an earthquake by comparing the capacity of the structure with the demand on the structure. This performance-based simplified seismic analysis technique can be used for a variety of purposes such as rapid evaluation of a large inventory of buildings, design verification for new construction of individual buildings, evaluation of an existing structure, and correlation of performance states of buildings to various amplitudes of ground motion. The procedure compares the capacity of the structure in the form of a pushover capacity curve with the demands on the structure in the form of an overdamped response spectrum. The method, originally proposed by Freeman (1978), was later implemented in many structural codes worldwide, although modified with several restrictions to its general potential. The application of the general CSM approach for the preliminary evaluation of the seismic performance of precast structures with either standard or innovative connections was assessed against experimental full-scale testing in Dal Lago and Molina (2018).

A retrofit case study of a typical precast concrete industrial frame structure employing tension-only dissipative braces with different device thresholds was carried out to assess the efficacy of the proposed retrofit technique and to frame the useful range of device threshold.

The building structural sections are shown in Fig. 4 and the main characteristics of the structural layout are resumed in Table 1. The structural grid is regular of $20 \mathrm{~m}$ by $10 \mathrm{~m}$, with 3 bays in each direction. Square columns with $60 \mathrm{~cm}$ side protrude from the base partially precast pocket foundation. Prestressed H-shaped internal beams and solid rectangular peripheral beams cover the $10 \mathrm{~m}$ span. Prestressed wing-shaped roof elements alternated by coverage barrel vault/shed elements cover the $20 \mathrm{~m}$ span (details on this roof system are available in Dal Lago 2017). 


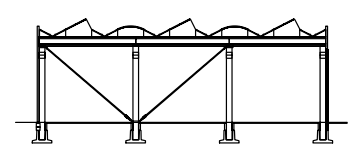

(a)

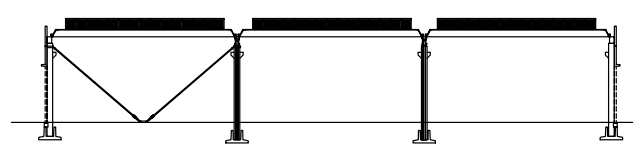

(b)

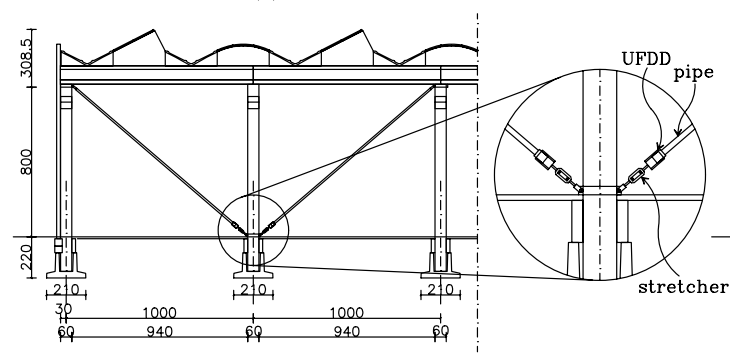

(c)

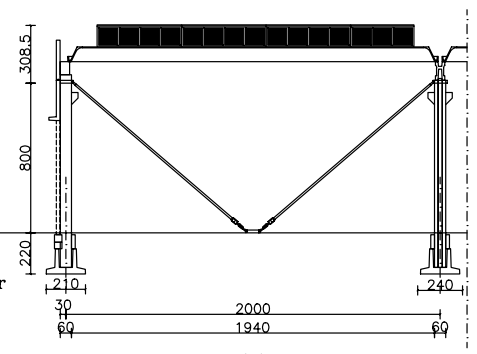

(d)

Fig. 4 Typical precast frame industrial structure with proposed retrofit intervention: a structural cross-section along the beam direction, $\mathbf{b}$ structural cross-section along the slab direction, $\mathbf{c}$ detail along beam direction, $\mathbf{d}$ detail along slab direction. Measures in $\mathrm{cm}$. Dissipative devices in green mounted over braces in blue. Stretchers are employed for tolerance adjustment only

Table 1 main properties of the structural layout

\begin{tabular}{lll}
\hline Column & Width $(\mathrm{m})$ & 0.6 \\
& Clear height $(\mathrm{m})$ & 8 \\
& Long. steel $(\%)$ & 1 \\
Frame layout & Transv. steel $(\%)$ & Not specified \\
& Grid size $(\mathrm{m} \times \mathrm{m})$ & $20 \times 10$ \\
& Distributed mass $\left(\mathrm{kg} / \mathrm{m}^{2}\right)$ & 300 \\
& No. of bays $/$ naves & $3 / 3$ \\
& Diaphragm & Flexible \\
Material & Cladding panel arrangement & Isostatic \\
& Concrete strength $\mathrm{f}_{\text {ck }}(\mathrm{MPa})$ & 45 \\
& Reinf. steel yield str. $\mathrm{f}_{\mathrm{yk}}(\mathrm{MPa})$ & 450 \\
Dissipative device & Brace steel yield str. $\mathrm{f}_{\mathrm{yk}}(\mathrm{MPa})$ & 235 \\
& Initial stiffness $(\mathrm{kN} / \mathrm{m})$ & Very high \\
& Threshold load & Variable \\
& Brace length $(\mathrm{m})$ & 12.8 \\
\hline
\end{tabular}

\section{Structural model}

The structural model of one frame excerpted in the direction of the beams was considered for the investigation, although the results would be similar for the frame in the direction of the slab elements. The difference would basically rely only upon a higher clear height of the column enlarged by the beam depth, since the beam follows the rotation of the column element in this direction. The single frame model is to be considered appropriate whether one bracing system is installed on each two-directional frame, or whether a rigid diaphragm is provided by the structural layout, which is however rare for precast industrial frame structures (Dal Lago and Ferrara 2018, Dal Lago et al. 2019). Installing 
dissipative braces on single frames of a building with roof system with flexible diaphragm may jeopardise every beneficial effect, due to the ineffective restraining of the unbraced frames by the adjacent braced ones. Intended or unintended stiffening effects of the cladding panels covering the perimeter of the building are neglected. The structural conceptual models are shown in Fig. 5 for both frame only and braced frame structures. It is reminded that, although these graphs are edited on the basis of a numerical model, which will be explained further on, they are introduced at this stage only to illustrate the assumptions at the basis of the analytical calculation shown in the present chapter. Seismic masses are assumed lumped in correspondence of the column top; column elements are assumed to be perfectly clamped at their base (pocket foundation) and perfectly hinged at the top around the horizontal axis orthogonal to the sketch; all columns, to which a non-linear behaviour in bending is attributed, are assumed to have the same displacement; the diagonal braces act in tension as springs with non-linear behaviour and freely deform in compression.

\section{Evaluation of the capacity curve and implementation of the capacity spectrum method}

In the following, a procedure of general applicability to precast frame buildings is developed, and numerical values associated to the specific reference building are introduced as worked examples.
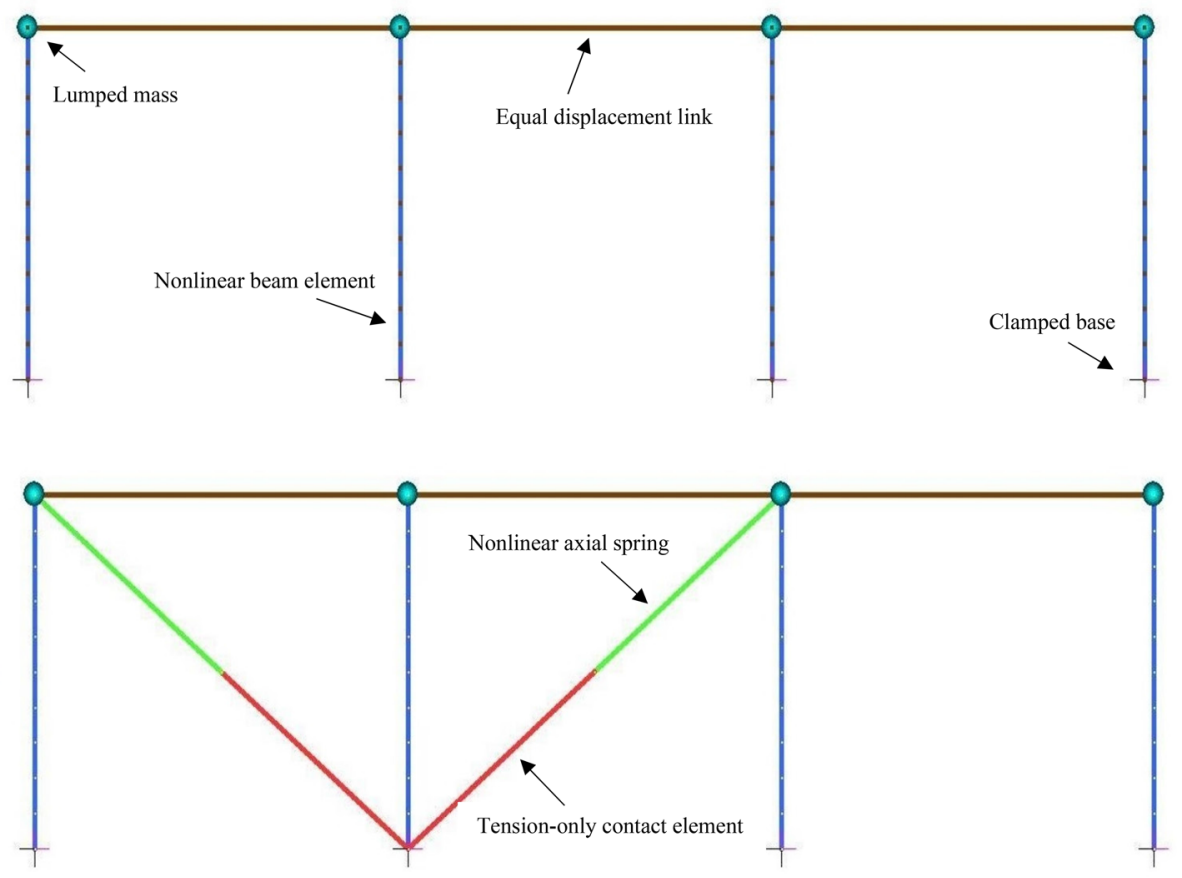

Fig. 5 Structural modelling strategies: a original unbraced frame, and $\mathbf{b}$ retrofitted braced frame 
Concrete class B45/55 is modelled with a Sargin constitutive model following Model Code 90 bulletin formulation ( $f i b$ 1990). An elastic-plastic model was adopted for steel, neglecting the material hardening, also in view of the scarce interest of the plastic behaviour range of reinforcement, being the objective of the retrofit intervention a seismic drift within the elastic field. It is also to be reminded that a stable plastic hysteresis and subsequential energy dissipation are achieved only when sufficient confinement of concrete core and bars is exerted by the transverse reinforcement, which is in most cases insufficient for existing buildings not designed and detailed for ductility.

The monotonic capacity curve is defined by 3 linear branches characterised by 2 points only, apart from the origin: the cracking and the yielding points. The post-yielding branch is considered constant, again following the assumption described above.

The horizontal load $P_{c r}$ associated to cracking is simply found by imposing the decompression limit of the concrete cross-section, assuming the section was already cracked due to previous events, as per (1). The axial load $N$ is needed for this step, which is calculated by simply multiplying the distributed mass (which includes the proper portion of cladding panel mass) by the single grid size, assumed equal for all the columns, under the assumption that for the edge column the mass of the horizontal suspended cladding panels compensates the absence of half slab. The cracking displacement is found by considering the elastic deformation of the plain cross-section, as per (2):

$$
\begin{gathered}
\mathrm{P}_{\mathrm{cr}}=\mathrm{Nh} /(6 \mathrm{H})=7.5 \mathrm{kN}(\text { per column }) \\
\delta_{\mathrm{cr}}=P_{\mathrm{cr}} /\left(3 \mathrm{E}_{\mathrm{cm}} \mathrm{I}_{\text {plain }} / H^{3}\right)=3.0 \mathrm{~mm}
\end{gathered}
$$

where $h$ is the section depth, $H$ is the clear span of the column, $E_{\mathrm{cm}}$ is the mean Young modulus of concrete and $I_{\text {plain }}$ is the gross second moment of the area of the idealised cross-section.

The yielding load $P_{y}$ is found by imposing the translational and rotational equilibria to the cross-section under imposed axial load $N$ and yielding strain $\varepsilon_{y}$ of the extreme bar layer, as per (3). The yielding displacement $\delta_{y}$ is found by numerically solving the differential equation of the inelastic line, integrating the curvature distribution over the beam twice.

$$
\begin{gathered}
\mathrm{P}_{\mathrm{y}}=\mathrm{M}_{\mathrm{y}}\left(\mathrm{N} ; \varepsilon_{\mathrm{y}}\right) / \mathrm{H}=61.9 \mathrm{kN}(\text { per column }) \\
\delta_{\mathrm{y}}=103.1 \mathrm{~mm}(\text { numerically integrated })
\end{gathered}
$$

The segmentary trilinear monotonic curve $P_{l}(\delta)$ associated to a column is then simply multiplied by the number of columns $n_{c o l}$ to get that of the frame. Second order effects, often remarkably relevant for precast industrial frame buildings, were taken into account in the definition of the base shear of the frame $P_{f}$ as per (5).

$$
P_{f}(\delta)=n_{c o l} P_{1}(\delta)-n_{c o l} N \delta / H
$$

The capacity curve of the frame structure obtained is plotted in Fig. 6a. The addition of the retrofitting bracing system modifies this curve as shown in Fig. 6a with reference to different device thresholds.

The brace systems are supposed to be post-installed in the industrial buildings as shown in Fig. 4a. The dissipative device with maximum assumed threshold of $200 \mathrm{kN}$ 


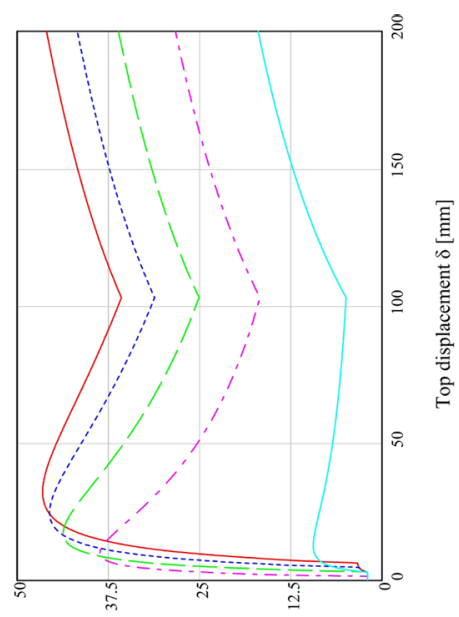

[\%] bəร ๔
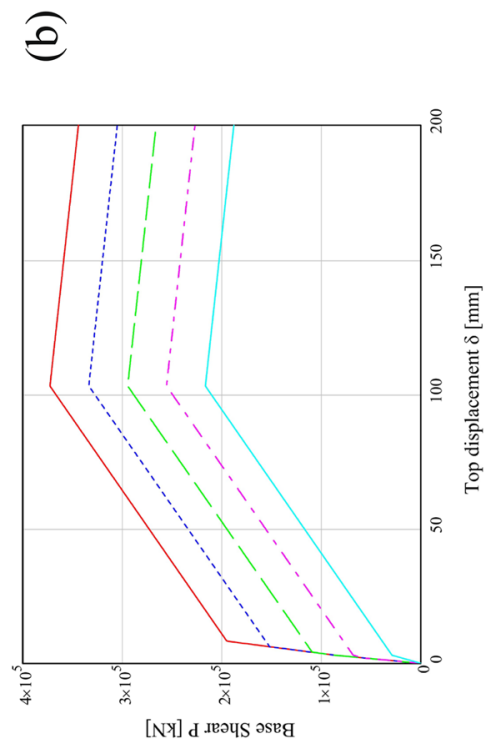

ชิ

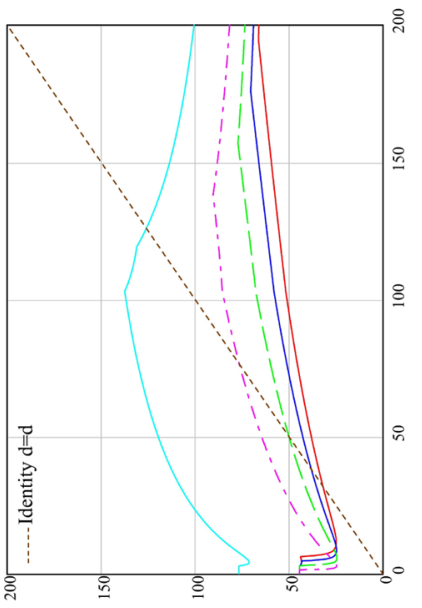

ริ

节

胥

$\Xi$

胥

วิ

氖

范

芯

is

ऐै

寻

芯气

目

ป

$\ddot{s}$

응

के

곤

.

吾

妾妾辛

응으응

"

$\sqrt{\sigma}$

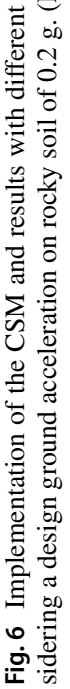


is linked at the base with a stretcher which is pinned to a steel plate connected with the column, and at its top to the steel tube which covers the gross length of $12.8 \mathrm{~m}$ (net tube length $11.2 \mathrm{~m}$ ). A tube with diameter $101.6 \mathrm{~mm}$ and thickness $6.3 \mathrm{~mm}$ was adopted. Such a profile was selected to ensure its strength even under friction peaks (in case a device based upon friction is employed), conservatively checking that the force corresponding to the attainment of the design yield strength is associated to a force higher than the double of the design threshold $P_{t h}$ (see in Eq. 6)

$$
A_{b} f_{y k} / \gamma_{m} \geq 2 P_{t h}
$$

In this case the design brace yield load results $1.89 \times 235 / 1.05=423 \mathrm{kN}$, which is higher than $2 \times 200=400 \mathrm{kN}$. The tube profile was also selected to limit bending deformation due to its own self weight along the horizontal projection of its clear span, which results lower than L/400. Through the weak tensioning applied by the stretcher, the tube is aligned in position avoiding mounting tolerances.

The brace stiffness $K_{b}$ is calculated assuming a rigid behaviour of the dissipative device, thus relying on the axial stiffness of the tubular profile, equal to about $30 \mathrm{kN} / \mathrm{mm}$ for the one adopted. The monotonic behaviour is then defined by an elastic branch characterised by the above-described stiffness followed by a plateau horizontal branch as long as the maximum stroke of the dissipative device. The point of discontinuity occurs at the threshold load $P_{t h}$, which more specifically is the dynamic friction threshold load. This model is similar to the one adopted in Dal Lago et al. (2017). The capacity curve of the bracing system is referred to the horizontal top displacement $\delta$ by properly orienting the force associated to the bracing system to its horizontal component $P_{b}$ as per (7).

$$
\begin{aligned}
\mathrm{P}_{\mathrm{b}}(\delta)= & \text { if }\left\{\delta<\mathrm{P}_{\mathrm{th}} /\left[K_{\mathrm{b}} \cos (\mathrm{a} \tan (\mathrm{H} / \mathrm{D}))\right] ;\right. \\
& \left.\delta K_{\mathrm{b}} \cos ^{2}(a \tan (H / D)) ; \mathrm{P}_{\mathrm{th}} \cos (\mathrm{a} \tan )\right\}
\end{aligned}
$$

The capacity curves of the frame structure braced with devices having different thresholds are obtained as a simple sum of the two contributions. Figure 6a also contains several capacity curves corresponding to devices with different threshold.

The CSM requires, as a further step to the definition of the capacity curve, the definition of the equivalent viscous damping curve. In order to obtain it, the hysteretic laws of frame and brace were defined as follows: a Takeda rule (Takeda et al. 1970) is set for the frame. This rule is different for the 3 linear branches: in the uncracked branch, the energy dissipation is null; in the cracked elastic branch the energy dissipation is shown in Fig. 7a; in the plastic branch the energy dissipation is shown in Fig. 7b. For both these ranges, the considered energy dissipation refers conservatively to cycles successive than the first, assuming the cyclic action of the earthquake. The energy dissipated by the frame $E_{d, f}$ is calculated as per (9), after having defined in (8) the unloading stiffness $K_{f \text {,unload }}$.

$$
\begin{gathered}
K_{\mathrm{f}, \text { unload }}(\delta)=\text { if }\left\{\delta<\delta_{\mathrm{y}} ;\left[P_{\mathrm{f}}(\delta)+P_{\mathrm{f}}\left(\delta_{\mathrm{cr}}\right)\right] /\left(\delta+\delta_{\mathrm{cr}}\right) ;\right. \\
\left.\left(\delta_{\mathrm{y}} / \delta\right)^{0.4}\left[P_{\mathrm{f}}\left(\delta_{\mathrm{y}}\right)+P_{\mathrm{f}}\left(\delta_{\mathrm{cr}}\right)\right] /\left(\delta_{\mathrm{y}}+\delta_{\mathrm{cr}}\right)\right\} \\
E_{\mathrm{d}, \mathrm{f}}(\delta)=\operatorname{if}\left\{\delta<\delta_{\mathrm{cr}} ; 0 ; 2 P_{\mathrm{f}}(\delta)\left[\delta-\left[P_{\mathrm{f}}(\delta) / K_{\mathrm{f}, \text { unload }}(\delta)\right]\right]\right\}
\end{gathered}
$$

The kinematic hardening hysteretic law (see Eq. 10) was assigned to the dissipative device, as shown in Fig. 7c, again following the model adopted in Dal Lago et al. (2017). 


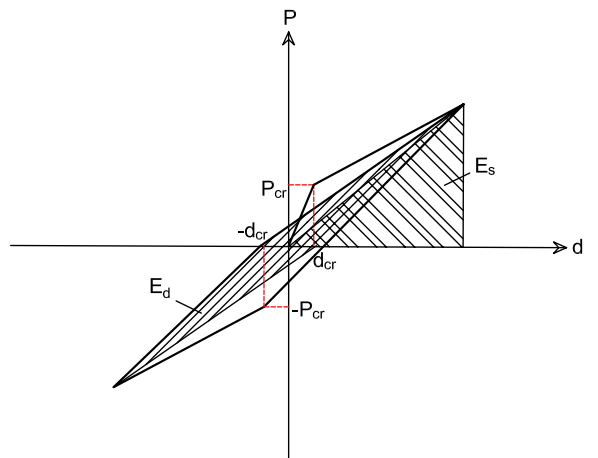

(a)

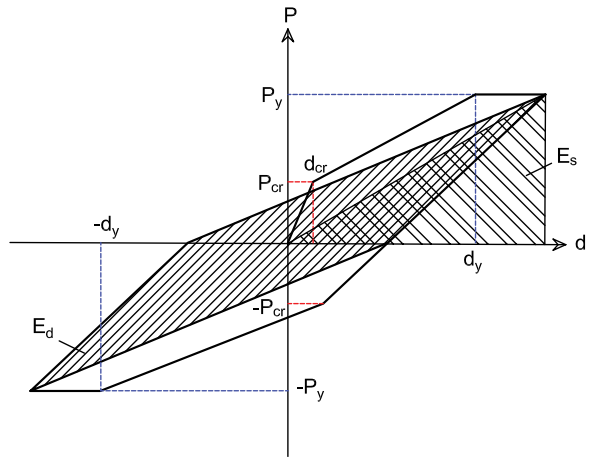

(b)

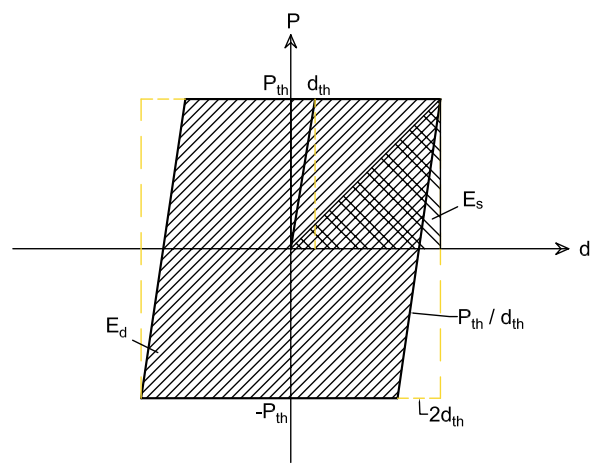

(c)

Fig. 7 Dissipation of energy considered for: a frame in pre-yielding condition (Takeda), $\mathbf{b}$ frame in postyielding condition (Takeda), and $\mathbf{c}$ full bracing system (Kinematic Hardening)

$$
E_{\mathrm{d}, \mathrm{b}}(\delta)=4 P_{\mathrm{th}}\left[\delta-P_{\mathrm{th}} / K_{\mathrm{b}}\right]
$$

From this data, the evaluation of the Equivalent Viscous Damping (EVD) curve $\zeta_{e q}(\delta)$ is obtained based on the proportion of the dissipated energy to the elastic energy equivalent to that of an elementary damper (see Eq. 11).

$$
\zeta_{\mathrm{eq}}(\delta)=\zeta_{0}+\left[E_{\mathrm{d}, \mathrm{f}}(\delta)+E_{\mathrm{d}, \mathrm{b}}(\delta)\right] /\{] /\left\{4 \pi\left[E_{\mathrm{s}, \mathrm{f}}(\delta)+E_{\mathrm{s}, \mathrm{b}}(\delta)\right]\right\}
$$

where $\zeta_{0}$ is the basic viscous damping (considered equal to $2 \%$ in the present study), $E_{d}$ is the dissipated energy as previously described, and $E_{s}$ is the elastic deformation energy computed by Eq. (12)

$$
E_{\mathrm{s}}(\delta)=\delta\left(P_{\max }+\left|P_{\min }\right|\right) / 4
$$

where $\mathrm{P}_{\max }$ and $\mathrm{P}_{\min }$ are the maximum and minimum base shear of the braced frame, respectively.

The EVD curves associated to frame only and to braced frame with various threshold loads are plotted in Fig. 6 b.

The final step of the CSM procedure consists in finding the Performance Point (PP) associated to a seismic event. The response spectrum of Eurocode 8 was employed 
referring to a subsoil type B. In particular, the displacement spectrum is employed through the definition of an apparent period $T_{a p p}$ as per (13).

$$
\begin{gathered}
T_{\text {app }}(\delta)=2 \pi \sqrt{ }\left\{\delta m /\left[P_{\mathrm{f}}(\delta)+P_{\mathrm{b}}(\delta)\right]\right\} \\
S_{\mathrm{d}}\left(\delta ; \zeta_{\mathrm{eq}}\right)=S a\left(T_{\mathrm{app}} ; \zeta_{\mathrm{eq}}\right)\left[T_{\mathrm{app}}(\delta) /(2 \pi)\right]^{2}
\end{gathered}
$$

where $m$ is the vibrating mass.

The PP is then found as the smaller intersection between the displacement spectrum $S_{d}\left(\delta ; \zeta_{e q}\right)$ and the line corresponding to the identity $d=d$. Figure $6 \mathrm{c}$ shows this final step of the CSM for a given design ground acceleration $a_{g}$ on rocky soil (type A) of $0.2 \mathrm{~g}$.

This procedure allows not only to derive a single PP for a given $a_{g}$, but also to derive Performance Series (PS) associated to a set of values of design acceleration. The procedure of finding of the single PPs was automatised, and the PSs evaluated are shown in Fig. 8.

The seismic performance of the structural assembly is resumed by six quantities, of which three absolute and three relative):

(a)

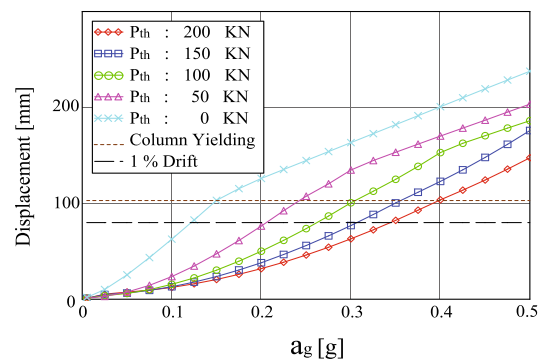

(b)

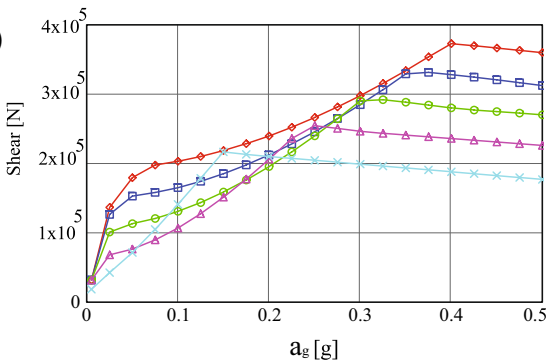

(c)

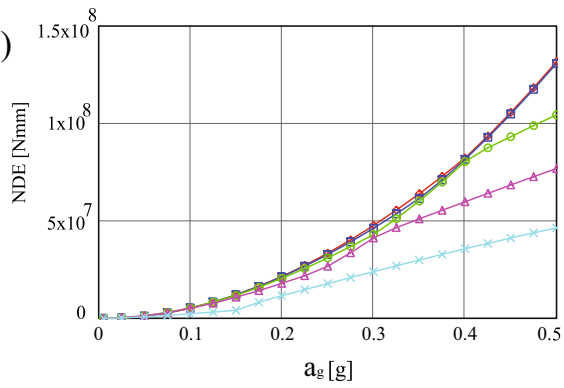

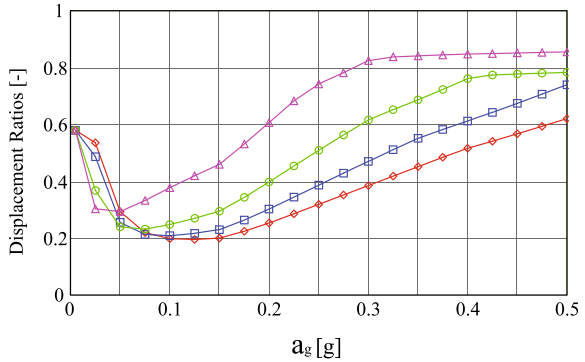
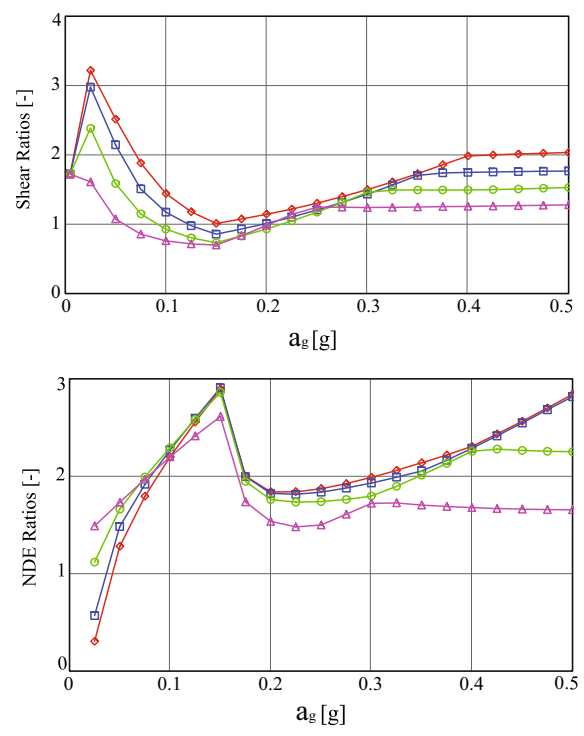

Fig. 8 Evaluation of: a performance displacement, b performance shear, and c normalised dissipated Energy and their corresponding ratios by implementing CSM considering various devices threshold loads 
- Absolute top displacement

- Top displacement ratio (absolute top displacement of the braced frame divided by absolute top displacement of frame only)

- Absolute base shear

- Base shear ratio (absolute base shear of the braced frame divided by absolute base shear of frame only)

- Normalised dissipated energy (defined as the energy dissipated by a single equivalent cycle of the structure at the performance displacement)

- Normalised dissipated energy ratio (absolute normalised dissipated energy of the braced frame divided by normalised dissipated energy of frame only)

The CSM is a method which does not allow to evaluate the energy dissipated during a hypothetical earthquake event. The Normalised Dissipated Energy (NDE) as defined above was introduced to give to the designer an idea of the potential extent of dissipation to which the structural assembly is subjected. The most useful interpretation of NDE displays in comparisons: a system with low NDE is subjected to limited mechanical non-linearity, whilst a system with high NDE indicates that a large hysteresis may occur under the considered earthquake event. The interpretation may appear controversial for the considered case: frame structures only provide better performance when NDE is low, since non-linear hysteresis is associated with structural damage; on the contrary, frames with dissipative bracing show better performance with high NDE, since it indicates a better use and exploitation of the dissipative device, at least in the field where the displacement is lower than the frame yielding one.

The plot in Fig. 8a referring to absolute performance displacement is shown together with two horizontal lines referring to the standard Damage Limit State condition of attainment of $1 \%$ of drift $(80 \mathrm{~mm})$ and the yielding displacement. The plots can be interpreted in two ways: according to the vertical approach, in correspondence of the yielding $a_{g}$ for the bare frame, corresponding to $0.15 \mathrm{~g}$, the efficacy of the dissipative bracing displays when considering that the displacement is lowered from 110 for the frame only to $47,30,24$, and $21 \mathrm{~mm}$ for a threshold load of $50,100,150$, and $200 \mathrm{kN}$, respectively; according to the horizontal approach, the yielding $a_{g}$ increases from 0.15 for the frame only to $0.21,0.26,0.31$, and $0.36 \mathrm{~g}$ for a threshold load of 50, 100, 150, and $200 \mathrm{kN}$, respectively. It is worth to note that the relative displacement curves tend to a horizontal asymptote for relatively large design accelerations, which corresponds to a range of limited efficiency of the bracing. The higher the device threshold load, the higher acceleration denotes this transition. The graph showing the relative displacement highlights that the points of maximum exploitation of the device for the relative reduction of the displacement, corresponding to the minimum of the series, have lower values for increasing device thresholds, as expected, and corresponds to higher $a_{g}$. This has as a consequence that weaker devices appear to be more effective than stronger devices for low-intensity design earthquakes.

Regarding the performance shear, the introduction of the dissipative bracing tends to increase it due to its stiffening effect. It is also to be reminded that the bracing attracts shear in a local portion of the structure, instead of distributing it equally among all columns as typical of the frame system only, which should be checked against possible activation of shear failure mechanisms in the columns. However, if looking at the relative shear, a range of ratios (slightly) lower than unity is found, which is the result of the counter-balancing effect of the reduction of global drift by the dissipative bracing and thus a strong reduction in the shear attributed to the whole frame. Both absolute and relative performance shear 
curves of the retrofitted structures show a tendency to match the slope of that of the frame only after the dissipative device attains the threshold load.

Considering the normalised dissipated energy, the graph referring to the absolute values shows three distinct branches: an initial phase with negligible energy dissipation, corresponding to a purely elastic hysteresis of both structure and bracing; a middle phase with a parabolic-like increase, being the energy dissipated by devices with different threshold loads very similar and progressively larger than that of the frame only; a final linear-like branch departing from acceleration values increasing with the device threshold load. The relative normalised dissipated energy graph shows a peak in correspondence of the yielding displacement of the frame only, where after this value its reduction is due to the increasing contribution of energy dissipation by the base of the columns.

\section{Non-linear time history analysis and comparison with CSM}

Since CSM is a simplified method which can be effectively employed to frame the expected seismic performance of a structural assembly whose dynamics is predominantly affected by a single mode as a more powerful instrument than elastic response spectrum analysis, and it also does not account for the detailed time history of an earthquake event, its efficiency in estimating the seismic performance of the non-linear structural system under consideration was assessed through the comparison with the results from Non-linear Time History Analysis (NTHA) for selected cases. It is reminded that the more general task of a check of the efficiency of CSM with reference to full-scale cyclic and pseudo-dynamic tests on fullscale precast concrete structures is analysed in Dal Lago and Molina (2018).

Numerical models were set in the structural code Straus7 (G + D Computing 2010), as shown and previously commented in Fig. 5, following the aim of a perfect simulation of the model employed for the application of the CSM. The mechanical non-linearity of the column beam elements was defined by introducing the non-linear moment-curvature diagram. The diagram introduced for all elements was defined as tri-linear on the basis of the curvatures associated to the relevant points of the force-displacement diagram shown in Fig. 6a for the frame only. Takeda hysteresis model was also attributed. To ensure the mono-lateral behaviour of the bracing, a tension-only contact element was introduced in series with the non-linear connection element to which the force-displacement monotonic curve of Fig. 7c was applied with a kinematic hardening hysteretic law.

The analyses were carried out considering both mechanical and geometrical non-linearities.

The capacity curves related to both braced and unbraced frame structures were checked to perfectly match those resulting from the CSM implemented procedure from non-linear static pushover analysis.

Ten artificially made accelerograms whose response spectrum is compatible with that of Eurocode 8 for subsoil type B were applied at the base of the considered structures. Artificial accelerograms instead of natural were employed in order to allow for a more sound comparison with the results obtained with the CSM, where the response spectrum of Eurocode 8 was used.

Three structures were considered: (a) frame only; (b) braced frame with $100 \mathrm{kN}$ of threshold load; (c) braced frame with $200 \mathrm{kN}$ of threshold load. Five base acceleration $a_{g}$ values were considered: $0.1 \mathrm{~g}, 0.2 \mathrm{~g}, 0.3 \mathrm{~g}, 0.4 \mathrm{~g}, 0.5 \mathrm{~g}$. Thus, a total of $10 \times 3 \times 5=150$ NTHAs were carried out. 
The results in terms of maximum displacement and shear are summarised and compared with CSM in Figs. 9 and 10, respectively. The results are provided in terms of both absolute values (left side graphs) and relative values (right side graphs), where the absolute values from NTHA are plotted with those obtained from CSM, and the relative values are expressed in terms of ratios between the values obtained from CSM and those obtained with NTHA.

It can be observed that for the lower value of design ground acceleration $a_{g}$, the two approaches give results which substantially match, due to the pseudo-elastic behaviour of both braced and unbraced structure. Considering the frame only, the CSM displacement curve falls in between the computed ones with NTHA, where the scatter of the numerical displacements increases with the acceleration. It is reminded that displacements in plastic field of the column bases can be attained only when proper geometric ratio and detailing of the transverse reinforcement is provided, which is often not the case of the buildings to be retrofitted. In terms of maximum shear, the curves fully align already at a design acceleration of $0.2 \mathrm{~g}$, which is the consequence of the attainment of the yield shear load of the frame.

(a)

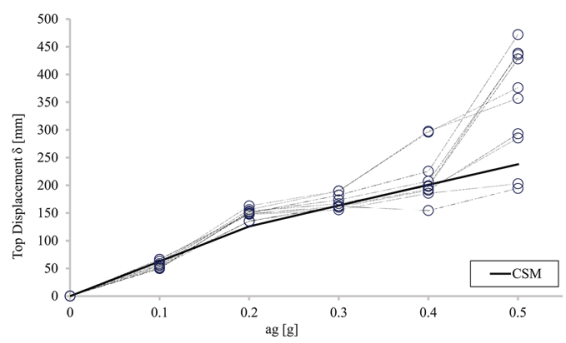

(b)

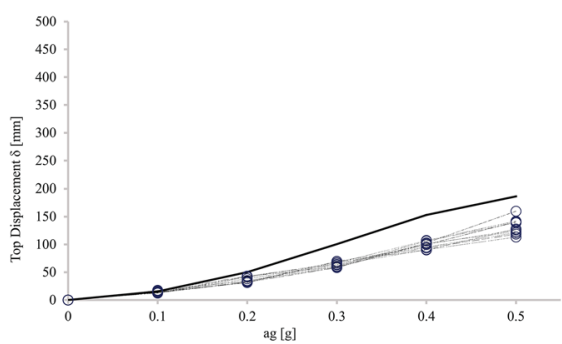

(c)

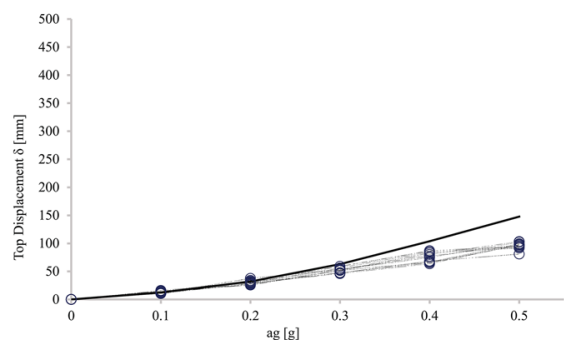

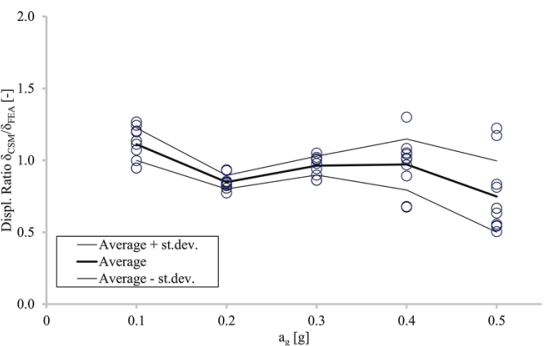
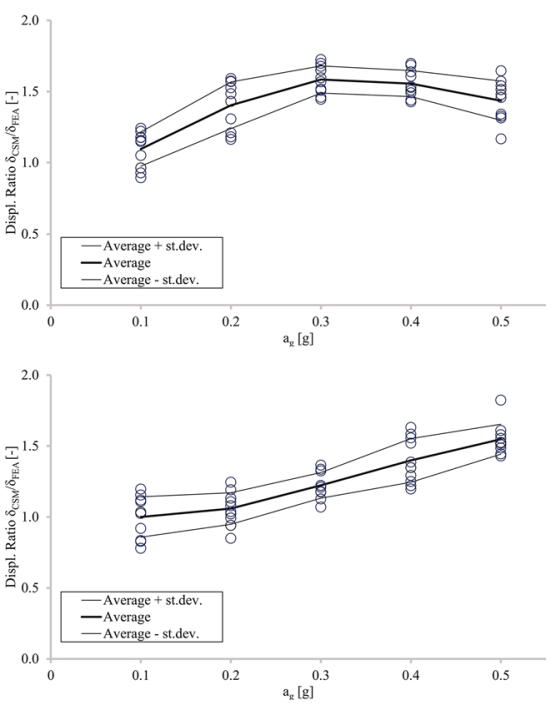

Fig. 9 Maximum top displacement and displacement ratios from NTHA and CSM for the models with: a original unbraced frame, b retrofitted braced frame with device threshold set to $100 \mathrm{kN}$, and $\mathbf{c}$ retrofitted braced frame with device threshold set to $200 \mathrm{kN}$ 
(a)

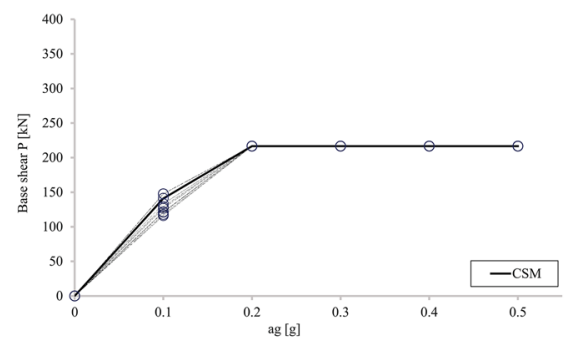

(b)

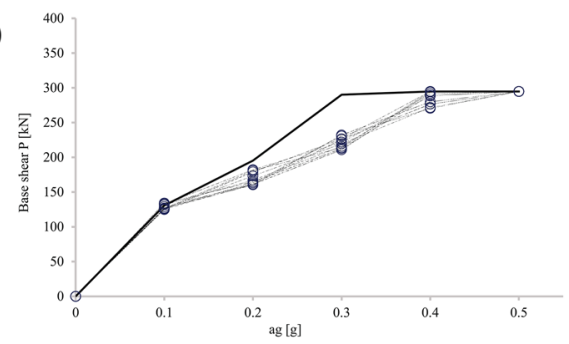

(c)

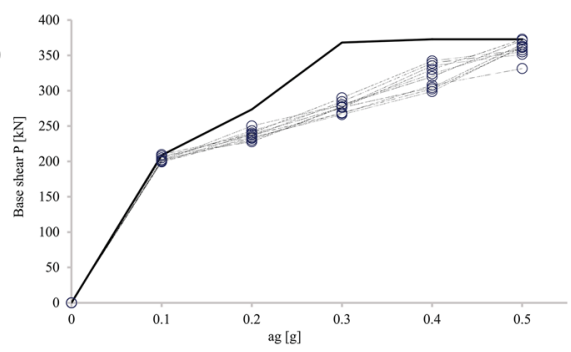

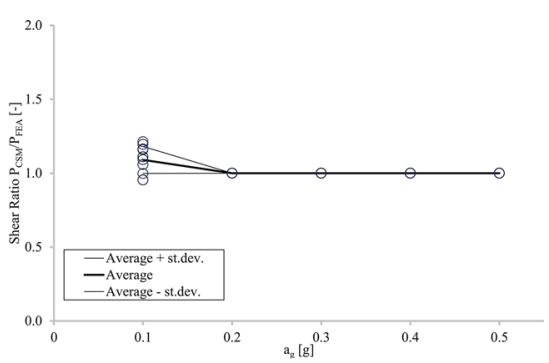
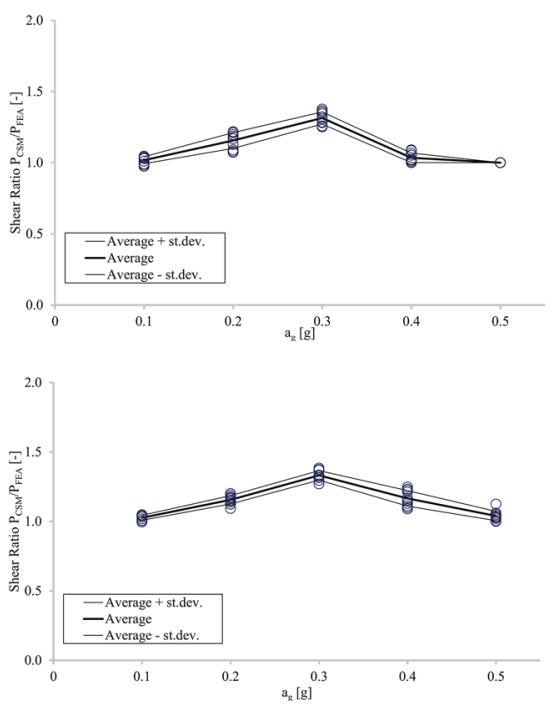

Fig. 10 Maximum base shear and base shear ratios from NTHA and CSM for the models with: a original unbraced frame, b retrofitted braced frame with device threshold set to $100 \mathrm{kN}$, and c retrofitted braced frame with device threshold set to $200 \mathrm{kN}$

When considering the braced structure, it can be observed that an increasing scatter between CSM and NTHA displacements occur with high accelerations, with those computed via CSM denoting a conservative scatter progressive with the acceleration. Similar comments apply also for the shear, but only limited to the behaviour branch prior to the attainment of the column yield displacement. After this value is attained, the base shear recorded in the analyses is the maximum, which was set for both CSM and NTHA. Thus, the differences in terms of shear between the two methods are less pronounced than the differences in terms of displacement.

\section{Parametric analysis of the seismic behaviour of precast structures retrofitted with the proposed technique}

The influence of different parameters which are identified as the most important for the determination of the seismic performance of an existing structure after the retrofitting intervention was studied by a parametric analysis. The parameters identified are those bolded in Table 1, where the associated values were varied starting from the reference 
building configuration as indicated in Table 2 . It is reminded that the parameter ranges and their combinations were not derived from a design process, since the aim is to simulate credible configurations of existing structural arrangements, which were built in different geographical areas and were designed since the " $40 \mathrm{~s}$ according to different regulations and safety approaches.

The reinforcement is conventionally distributed in 12 bars equally distanced along a perimeter distanced by $1.5 \Phi$ from the perimeter of the column. The diameter of the bars is calculated by simply considering the area of steel from the geometric reinforcement ratio, attributing it in equal parts to the 12 positions set. Although this may lead to unrealistic diameters, it is deemed that not many differences would arise in case of a more refined distribution. The performance series resulting from the parametric analysis are summarised in Fig. 11 and in Fig. 12, where the plots of Fig. 12 refer to the ratio of the performance parameters associated to the retrofitted frame with device capacity of $100 \mathrm{kN}$ (shown in Fig. 11 in absolute terms) with the parameters associated to the original unbraced frame structure.

- Dissipative device threshold load

The influence of the variation of device threshold load was already shown in Fig. 8 and commented earlier.

- Column width

The column width is related to lateral stiffness and strength. It is observed that with increment in column section dimensions results are converging towards safer side, although this parameter seems not to be much effective in controlling displacement and normalised dissipated energy, at least in the range of low-medium accelerations up to about $0.3 \mathrm{~g}$. The impact of section dimensions variation on the performance shear is much more prominent. From performance shear and shear ratio curves, it can be deduced that as the section dimension is increased the performance shear is also increased. More negative impact for dimension increment is visible at high acceleration where at $a_{g}=0.3 \mathrm{~g}$ sections of $(700 \times 700)$ and $(800 \times 800) \mathrm{mm}$ are leading to almost four times more shear as compared to structure in which column sections of $(400 \times 400)$ $\mathrm{mm}$ are used.

- Grid size

Grid size is related to both column tributary mass and axial load on the columns. It is observed that with the increase of grid size, the capacity of the structure to contain the displacement reduces, as similarly observed for performance shear, which increases with the grid size. Higher impact can be observed at low-medium accelera-

Table 2 Range of values considered in the parametric analysis

\begin{tabular}{lll}
\hline Column & Width $(\mathrm{m})$ & $0.4-0.5-\mathbf{0 . 6}-0.7-0.8$ \\
& Clear height $(\mathrm{m})$ & $5-6-\mathbf{8}-10-12$ \\
Frame layout & Long. steel $(\%)$ & $0.5-\mathbf{1 . 0}-1.5-2.0-2.5$ \\
& Grid size $(\mathrm{m} \times \mathrm{m})$ & $8 \times 16-10 \times 20-\mathbf{1 2} \times \mathbf{2 4}-15 \times 30-18 \times 36$ \\
& Distributed mass $\left(\mathrm{kg} / \mathrm{m}^{2}\right)$ & $200-\mathbf{3 0 0}-400-500-600$ \\
Dissipative device & No. of bays $/$ naves & $1-2-\mathbf{3}-4-5$ \\
\hline
\end{tabular}

Bolded values are associated to the reference building 


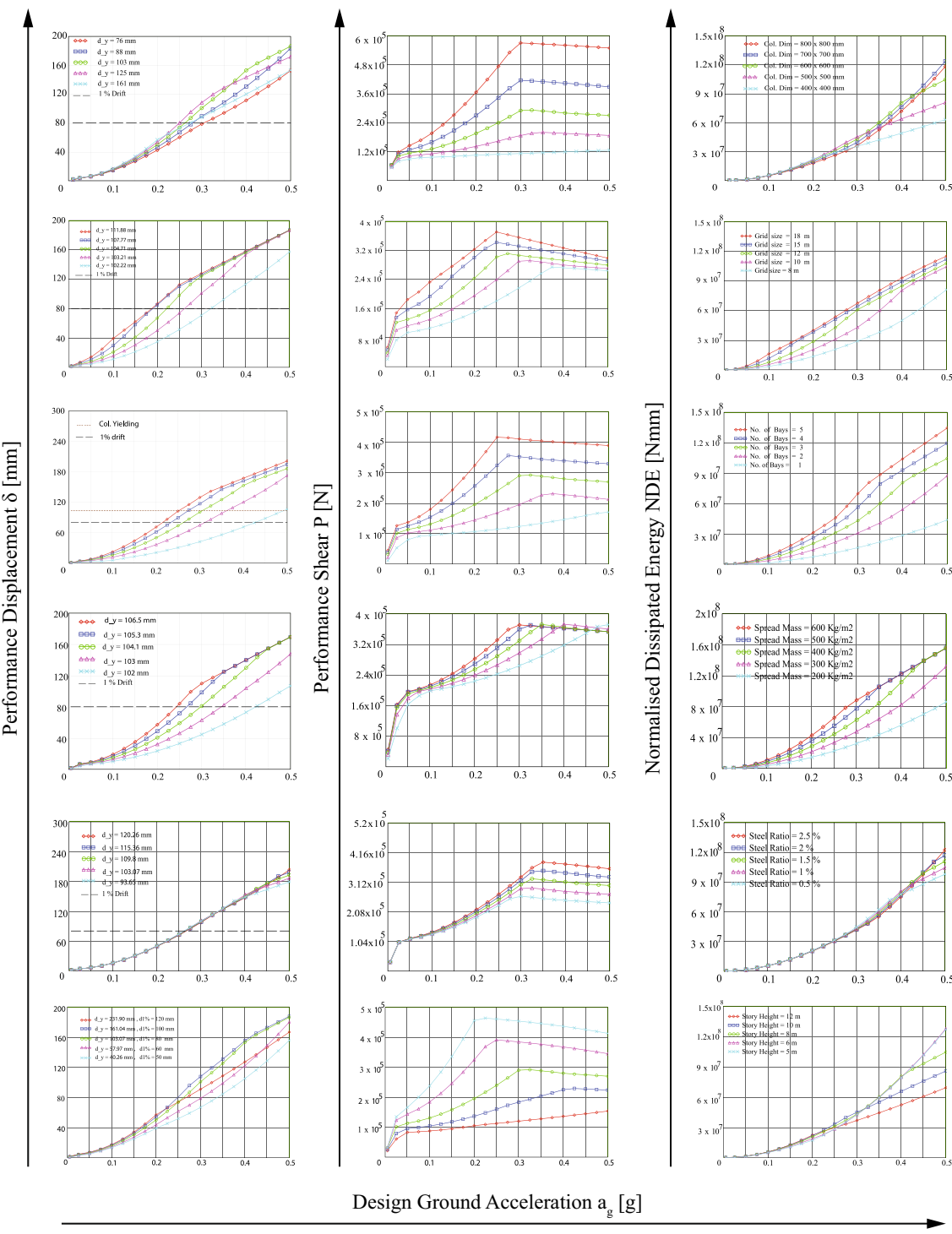

Fig. 11 Performance series from parametric analysis (absolute values): a column width, $\mathbf{b}$ grid size, $\mathbf{c}$ number of bays, $\mathbf{d}$ distributed mass, $\mathbf{e}$ steel ratio, and $\mathbf{f}$ storey height

tion up to $0.3 \mathrm{~g}$. Increase in grid size contrarily implies higher dissipation of energy, leading to a higher degree of use of the dissipative devices.

- Number of bays

The number of bays affects the ratio of the total vibrating mass and the stiffness/ strength of the building. It can be observed that fewer the number of bays, the more control displays on displacement. This effect is more impactful at lower acceleration. Similarly, larger shear is observed when increasing the number of bays. This 


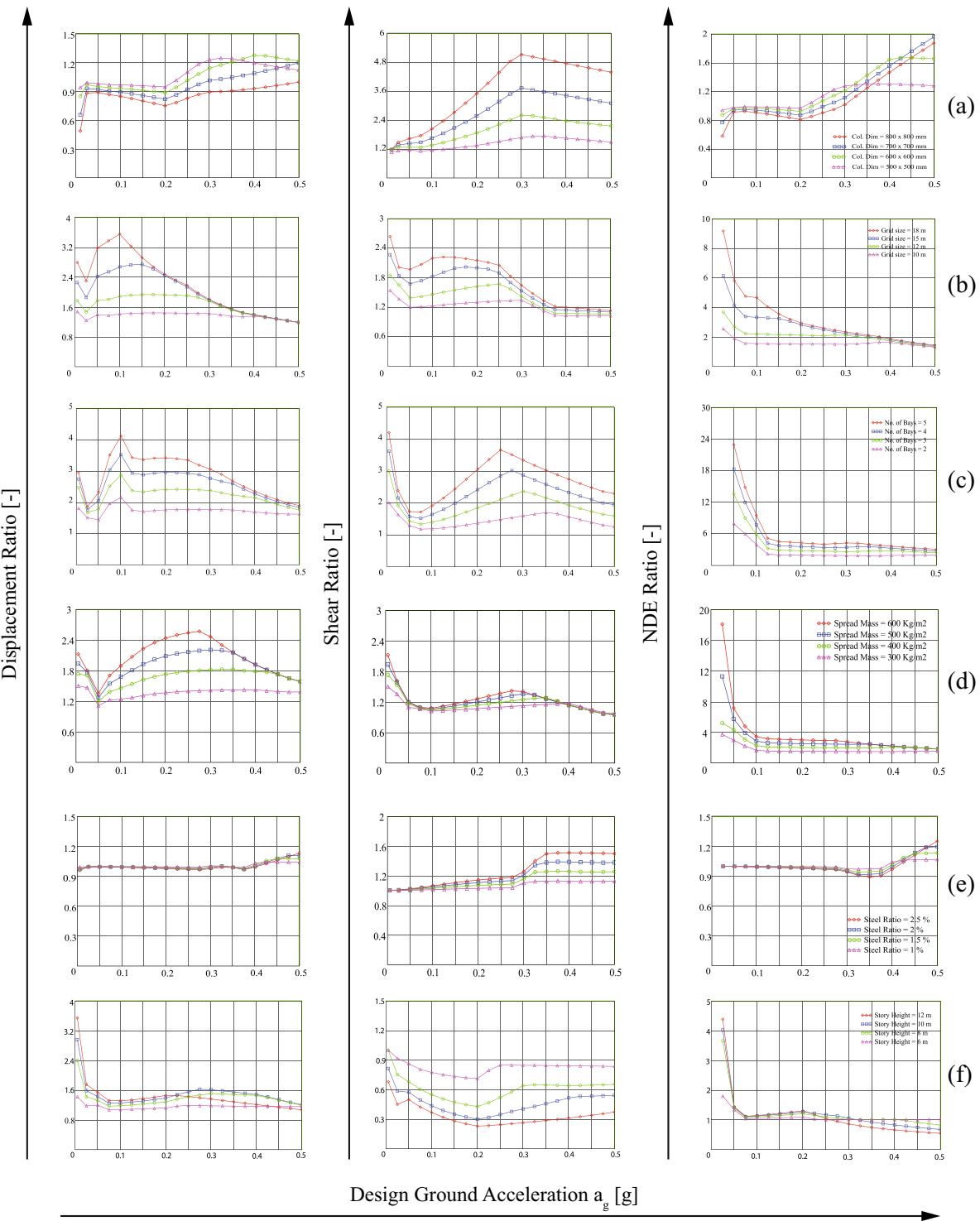

Fig. 12 Performance series from parametric analysis (ratios of absolute values over those corresponding to the benchmark unbraced frames): a column width, b grid size, $\mathbf{c}$ number of bays, $\mathbf{d}$ distributed mass, e steel ratio, and $\mathbf{f}$ storey height

behavior is prominent at accelerations between 0.2 and $0.3 \mathrm{~g}$. An opposite trend is observed for the normalised dissipated energy.

- Distributed mass

Distributed mass affects both vibration period and column axial load. It is observed that the lower the distributed mass, the higher reduction on the displacement. Regarding performance shear, the impact of distributed mass is limited. An opposite 
behaviour is observed for normalised dissipative energy, which increases with the distributed mass, highlighting a more severe use of the dissipative device.

- Steel ratio

Steel ratio affects mainly the post-cracking column stiffness and the column strength. Surprisingly, the steel ratio seems to have a very low effect on the seismic behaviour of the braced structure, with relevant variations observed only in shear and for high accelerations, with higher shear corresponding to higher steel ratio. The reason behind this result is to be identified in the fact that for low-medium accelerations the frame structure acts in elastic field, and thus the strength of the column does not play a role.

- Storey height

Storey height affects both column stiffness and base shear. This parameter has a relevant impact on the seismic response of the braced precast structure, being the reduction of displacement more prominent at lower accelerations. Performance shear has a strong dependency upon the storey height, being that associated to shorter columns much larger than that associated to taller columns. The normalised dissipated energy appears to be similar for the different storey heights at low-medium accelerations, whilst becoming more prominent for shorter columns at high accelerations.

\section{Design workflow of the retrofitting intervention and selection of the device threshold}

The workflow envisaged for the design of the retrofit intervention of an existing precast industrial structure with the proposed technique employing tension-only dissipative braces is schematically resumed in Fig. 13. It is specified that specific issues related to the seismic

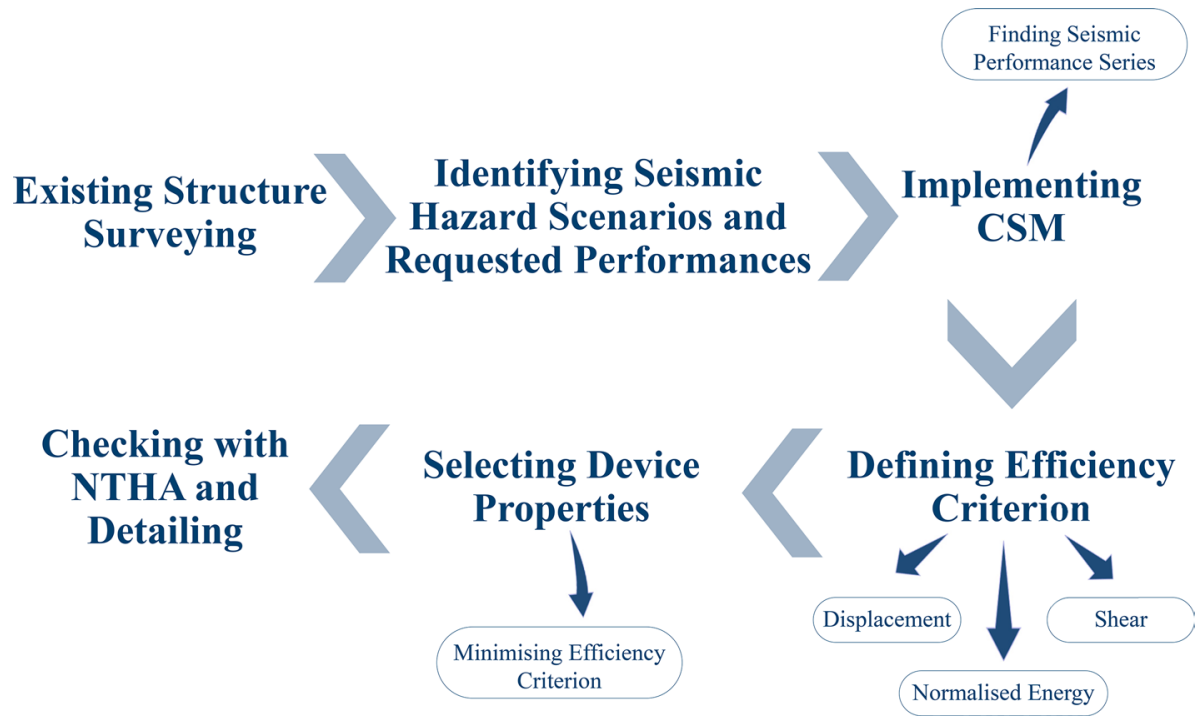

Fig. 13 Design flowchart 
behaviour of precast structure, such as cladding panel connections or deficient connections between horizontal elements, are to be solved separately from the present workflow.

The steps are commented in the following:

- Existing structure surveying

The geometrical, structural, and material detailing shall be defined based on a direct survey and on experimental tests on materials, or on the original drawing, or on a probabilistic framework. The parameters that are required for the computation of the capacity curve of the frame structure are, at least, those listed in Table 1 (excluding the last section on dissipative device).

- Identifying seismic hazard scenarios and requested performances

The seismic hazard scenarios can be determined based on the current existing classification of the seismic hazard, eventually including coefficients of importance higher than one on the basis of the importance of the construction and of its content. To the typical four earthquake design levels, with base accelerations related to increasing return periods, shall be associated performance levels. As shown in Fig. 14, the traditional approach for seismic retrofit interventions can be substantially improved with the use of the proposed retrofitting technique, which allows to tackle more severe performance requirements. For instance, the proposed technique may be proportioned so that the columns do not yield under the rare design earthquake and they moderately yield under the very rare design earthquake.

- Implementing CSM

Using the values of geometrical, frame and material properties, the CSM can be systematically employed for the evaluation of the performance series for the considered structural scheme with different threshold loads of the device and for different levels of base accelerations. A check has to be performed at this point identifying which threshold load meets the previously defined performance requirement at the associated earthquake design level.

- Defining efficiency criterion

The performance series, after having eliminated those not satisfying the performance criteria to be met, can be analysed through structural efficiency parameters. These parameters were introduced earlier. They are: (a) performance displacement ratio,

\begin{tabular}{|c|c|c|c|c|c|c|}
\hline & \multicolumn{5}{|c|}{ PERFORMANCE LEVEL } \\
\hline & & Drift $<0.5 \%$ & Drift $<1.0 \%$ & Drift $<\delta_{\text {yield }}$ & Drift $<1.5 \delta_{\text {yield }}$ & Drift $<\delta_{\text {ultimate }}$ \\
\hline \multirow{4}{*}{ 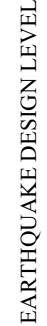 } & $\begin{array}{c}\text { Frequent } \\
(\mathrm{T}=43 \text { years })\end{array}$ & + & & & & \\
\hline & $\begin{array}{c}\text { Occasional } \\
(\mathrm{T}=72 \text { years) }\end{array}$ & & $\mathrm{x},+$ & & & \\
\hline & $\begin{array}{c}\text { Rare } \\
(\mathrm{T}=475 \text { years })\end{array}$ & & & + & & $\mathrm{x}$ \\
\hline & $\begin{array}{c}\text { Very Rare } \\
(\mathrm{T}=2475 \text { years })\end{array}$ & & & & + & \\
\hline
\end{tabular}

Fig. 14 Example of different allocation of target performance levels to earthquake design levels from traditional to dissipative bracing retrofit 
defined as the ratio of the performance displacement of the braced structure over that of the unbraced structure $\delta_{\text {braced }} / \delta_{\text {unbraced }}$; (b) performance shear ratio, defined as the ratio of the performance shear of the braced structure over that of the unbraced structure $P_{\text {braced }} / P_{\text {unbraced }}$; (c) normalised dissipated energy ratio, defined as the ratio of the normalised dissipative energy of the unbraced structure over that of the braced structure $E_{d, \text { unbraced }} / E_{d \text {,braced }}$. To be noted that the latter value is defined in inverse form with respect to the previous, in order to better guide the designer towards values consistently showing higher efficiency when minimising each performance parameter. Figure 15 shows an example of the trend of the above-defined performance parameters referring to the reference building analysed in the previous sections.

- Selecting device properties

The device properties (threshold load and stroke) may be defined based on the analysis of the previously obtained performance parameters. In particular, the device properties could be selected through minimisation of one of the above-described parameters. It is noted from the application of Fig. 15 that in some cases a minimum value is difficult to be obtained. Moreover, it is hard to define a single performance parameter to be considered, since all the three suggested parameters may have an important influence over the structural performance. It is therefore suggested to refer to a fourth parameter (d) which is a combination of the previously defined ones. In particular, the plot in Fig. 15 contains an equal weight combination ( $1 / 3$ displacement; $1 / 3$ shear; $1 / 3$ energy). It can be noted that the minimisation of the combined parameter series allows a meaningful device selection: the device threshold loads would be in the range $50-75 \mathrm{kN}, 125-150$ $\mathrm{kN}$, and $175-200 \mathrm{kN}$ for design accelerations of $0.1 \mathrm{~g}, 0.2 \mathrm{~g}$, and $0.3 \mathrm{~g}$, respectively. It is reminded that the performance parameters shall also meet the minimum requirements identified in the requested performance step.

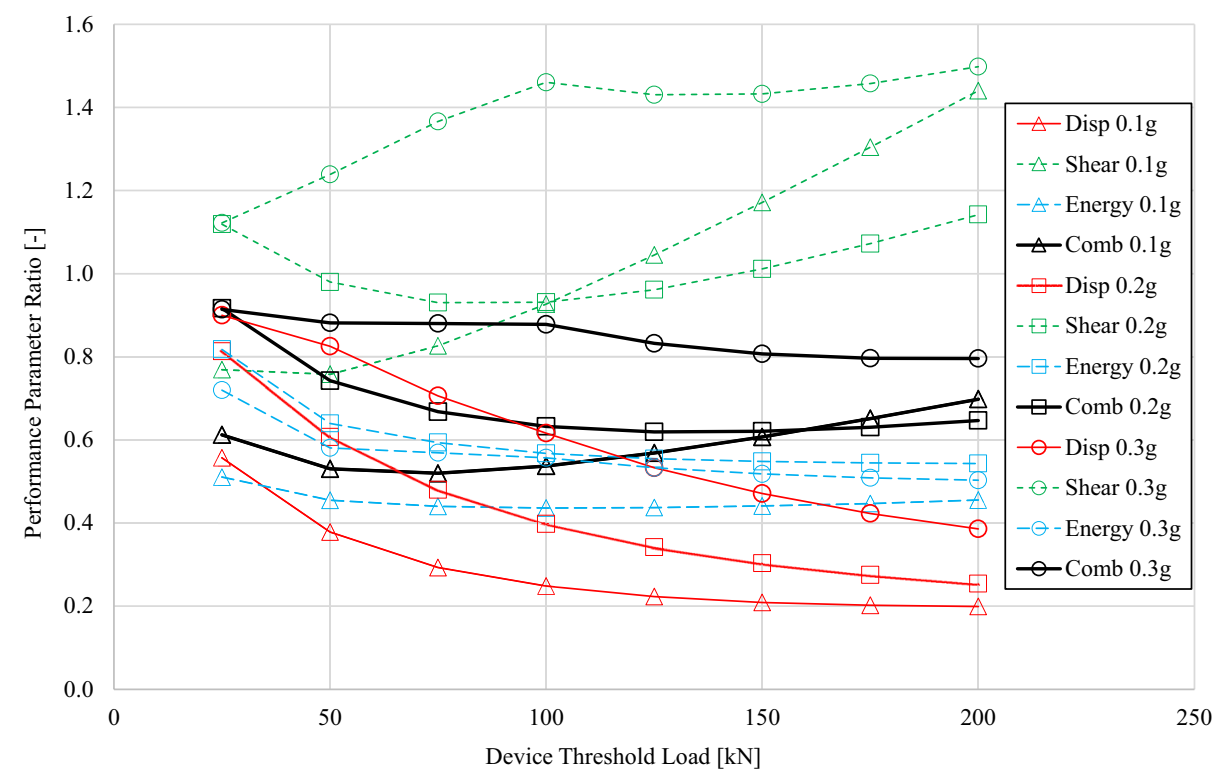

Fig. 15 Performance indicators for assigned structural assembly 
- Check with NTHA

In order to check the accuracy and reliability of the CSM simplified and quick design approach, the intervention as designed via CSM shall be validated through NTHA with a proper set of dynamic non-linear analyses under imposed accelerograms. The results, analysed with a probabilistic approach, would then be compared with the requested performances associated to the different seismic hazard scenarios previously identified. Whether the results would not meet the requirements, the procedure has to restart from the previous step, selecting of a different dissipative device (probably with higher threshold load), and then this final step has to be repeated until convergence is attained. Subsequently, the intervention can be drawn and designed in every detail.

\section{Conclusions}

In this paper, a novel retrofitting technique for precast concrete industrial frame buildings based upon tension-only monolateral dissipative devices mounted on steel braces was proposed. These braces act as energy fuses and can provide additional stiffness and relevant hysteretic damping to the structural behaviour since low drift cycles. A novel device is proposed based on friction mechanism, allowing for (a) higher specific energy dissipation thanks to rectangular-like cyclic shape and large triggering stiffness, (b) no influence of ratchet mechanisms, (c) limited damage even under heavy engagement, and (d) theoretically infinite cumulated displacement as far as the hysteresis occurs within the maximum and minimum displacements allowed by the external tube length.

The effectiveness of these dissipative braces was assessed considering a reference building typical of the heritage of precast concrete buildings in Europe. The CSM was employed to quickly although approximately evaluate the structural performance under earthquake action referring to 3 performance parameters: top displacement, base shear, and dissipated energy normalised over one cycle at the maximum top displacement. In order to check the accuracy and reliability of this approach, CSM outcomes were compared with the results obtained from Non-linear Time History Analysis. The comparison results suggest a remarkable accuracy in terms of maximum shear, while in terms of displacement the results obtained from both approaches show similar trends although scattering with higher acceleration, being the performance predicted with CSM on the safe side. Considering the design framing purpose of the CSM, this method is deemed to satisfactorily predict the non-linear behaviour of structure for the preliminary proportioning of the dissipative bracing, to be later more sophisticately checked with NTHA.

A numerical tool was programmed to quickly perform the CSM based on the following few initial parameters of the precast structure and the device: (a) Dissipative device capacity, (b) Steel ratio, (c) Story height, (d) Dimension, (e) Grid size, (f) Number of bays, (g) Distributed mass. A parametric study was then carried out by varying the values of the above-cited different parameters which can possibly affect the seismic response of precast frame structures in typical ranges. The effect of variation in these parameters was observed with above-mentioned key performance indicators and also through the ratio of the performance of the braced structure over that of the unbraced structure.

The proposed innovative bracing system shows great potential in providing seismic retrofitting for the existing precast building stock. All three performance indicators are important in 
assessing the most efficient slip/yield load threshold of the proposed device given an existing structure and its site. The combined indicator, equally weighted among the three above-cited indicators, could be suggested as the most desirable to get at the same time a relevant reduction of the structural displacement, mainly related to damage, a reasonable shear demand, in order to make an economical intervention, and a large energy dissipated by the device, so to better exploit its damping properties. Thanks to the numerical tool developed by utilising the CSM, the selection of the device most suitable for the retrofit intervention can be framed in few seconds of computational analysis and starting from few geometrical and mechanical parameters. However, since the CSM is a simplified method providing results with just a reasonable accuracy, as also proved by the comparison between the results from CSM and dynamic non-linear analyses with code-compatible artificial accelerograms, a proper set of dynamic non-linear analyses is suggested to be performed for the final check of the selected solution.

The future research work will be devoted to the detailed construction and local and subassembly testing of prototypes of the proposed device and brace based on friction, and to the extension of the application of the proposed technology to structural typologies other than precast.

Acknowledgements Prof. Fabio Biondini is acknowledged for co-tutoring Mr. Naveed alongside the development of his MSc thesis at Politecnico di Milano, which was related to the topic addressed in the paper.

Author Contributions BDL contributed to the original idea, provided guidance and supervision for the work, implemented the CSM procedure for precast structures. MN developed the structural FEM models, implemented the automatisation of the CSM procedure, organised the output results. MLT contributed to the original idea and physically conceived the tension-only dissipative device based on friction.

Funding Open access funding provided by Università degli Studi dell'Insubria within the CRUI-CARE Agreement. This research was developed independently by the Authors, without funding bodies.

Data availability Data and material related to the paper are available upon request to the authors.

Code availability Closed-source software was employed for the development of the work contained in the paper.

\section{Declarations}

Conflict of interest The first and corresponding author is partner of DLC Consulting srl of Milan, Italy, which is a Structural Engineering consultant company active in different fields, among which precast concrete structures and their retrofit. The author, however, does not envisage any explicit benefit to his financial/commercial activity from the research published in this paper. The second and third authors declare no conflict of interest.

Open Access This article is licensed under a Creative Commons Attribution 4.0 International License, which permits use, sharing, adaptation, distribution and reproduction in any medium or format, as long as you give appropriate credit to the original author(s) and the source, provide a link to the Creative Commons licence, and indicate if changes were made. The images or other third party material in this article are included in the article's Creative Commons licence, unless indicated otherwise in a credit line to the material. If material is not included in the article's Creative Commons licence and your intended use is not permitted by statutory regulation or exceeds the permitted use, you will need to obtain permission directly from the copyright holder. To view a copy of this licence, visit http://creativecommons.org/licenses/by/4.0/. 


\section{References}

ACNBC (Associate Committee on the National Building Code) (2005) National Building Code of Canada. Ottawa, Canada

Aiken ID, Nims DK, Whittaker AS, Kelly JM (1993) Testing of passive energy dissipation systems. Earthq Spectra 9(3):335-370

ASCE (American Society of Civil Engineers) (2010). ASCE/SEI 7-10: Minimum design loads for buildings and other structures. Reston, VA (USA)

Batalha N, Rodrigues H, Varum H (2019) Seismic performance of RC precast industrial buildings: learning with the past earthquakes. Innov Infrastruct Solut. https://doi.org/10.1007/s41062-018-0191-y

Belleri A, Brunesi E, Nascimbene R, Pagani M, Riva P (2015a) Seismic performance of precast industrial facilities following major earthquakes in the italian territory. ASCE J Perform Constr Facil 29(5):04014135

Belleri A, Marini A, Riva P, Nascimbene R (2017) Dissipating and re-centring devices for portal-frame precast structures. Eng Struct 150:736-745

Belleri A, Torquati M, Riva P, Nascimbene R (2015b) Vulnerability assessment and retrofit solutions of precast industrial structures. Earthq Struct 8(3):801-820

Bournas D, Negro P, Taucer F (2013) Performance of industrial buildings during the Emilia earthquakes in Northern Italy and recommendations for their strengthening. Bull Earthq Eng 12(5):2383-2404

Broderick BM, Elghazouli AY, Goggins J (2008) Earthquake testing and response analysis of concentrically-braced sub-frames. J Constr Steel Res 64:997-1007

CEN (Comité Européen de Normalisation) (2005) European Standard EN1998-3: 2005: Eurocode 8: Design of structures for earthquake resistance, Part 3: Assessment and retrofitting of buildings. Brussels, Belgium

Cook J, Rodgers GW, Macrae GA, Cook J (2018) Design and testing of ratcheting, tension-only devices for seismic energy dissipation systems. J Earthq Eng 24(2):328-349

Dal Lago B (2017) Experimental and numerical assessment of the service behaviour of an innovative longspan precast roof element. Int J Concr Struct Mater 11(2):261-273

Dal Lago B (2021) Vulnerability assessment of precast industrial facilities. In: Ferreira TM, Rodrigues H (eds) Seismic vulnerability assessment of civil engineering structures at multiple scales: from single buildings to large-scale assessment. Elsevier, Woodhead Publishing

Dal Lago B, Bianchi S, Biondini F (2019) Diaphragm effectiveness of precast concrete structures with cladding panels under seismic action. Bull Earthq Eng 17(1):473-495

Dal Lago B, Biondini F, Toniolo G (2017) Friction-based dissipative devices for precast concrete panels. Eng Struct 147:356-371

Dal Lago B, Biondini F, Toniolo G (2018a) Seismic performance of precast concrete structures with energy dissipating cladding panel connection systems. Struct Concr 19(6):1908-1926

Dal Lago B, Biondini F, Toniolo G (2018b) Experimental investigation on steel W-shaped folded plate dissipative connectors for precast cladding panels. J Earthq Eng 22(5):778-800

Dal Lago B, Biondini F, Toniolo G (2018c) Experimental tests on multiple-slit devices for precast concrete panels. Eng Struct 167:420-430

Dal Lago B, Ferrara L (2018) Efficacy of roof-to-beam mechanical connections on the diaphragm behaviour of precast decks with spaced roof elements. Eng Struct 176:681-696

Dal Lago B, Molina FJ (2018) Assessment of a capacity spectrum seismic design approach against cyclic and seismic experiments on full-scale precast RC structures. Earthq Eng Struct Dyn 47(7):1591-1609

Della Corte G, D’Aniello M, Landolfo R (2015) Field testing of all-steel buckling-restrained braces applied to a damaged reinforced concrete building. ASCE J Struct Eng 141(1):D4014004

Erochko J, Christopoulos C, Tremblay R, Choi H (2011) Residual drift response of SMRFs and BRB frames in steel buildings designed according to ASCE 7-05. ASCE J Struct Eng 137(5):589-599

Erochko J, Christopoulos C, Tremblay R, Kim HJ (2013) Shake table testing and numerical simulation of a self-centering energy dissipative braced frame. Earthq Eng Struct Dyn 42(11):1617-1635

Fahnestock LA, Ricles JM, Sause R (2007) Experimental evaluation of a large-scale buckling-restrained braced frame. ASCE J Struct Eng 133(9):1205-1214

FEMA (Federal Emergency Management Agency) (2009) FEMA P440A: effects of strength and stiffness degradation on seismic response. Washington DC, USA

fib (Fédération Internationale du Béton) (1990). Model Code 1990. Lausanne, Switzerland

Filiatrault A, Cherry S (1987) Performance evaluation of friction damped braced steel frames under simulated earthquake loads. Earthq Spectra 3(1):57-78

Filiatrault A, Tremblay R, Kar R (2000) Performance evaluation of friction spring seismic damper. ASCE J Struct Eng 126(4):491-499 
Fitzgerald TF, Anagnos T, Goodson M, Zsutty T (1989) Slotted bolted connections in aseismic design for concentrically braced connections. Earthq Spectr 5(2):383-391

Freeman SA (1978) Prediction of response of concrete buildings to severe earthquake motion. In: Douglas McHenry international symposium on concrete and concrete structures. Detroit, Michigan, USA. American concrete institute (ACI), SP-55: 589-605

G+D Computing (2010) Using Strand7 (Straus7): Introduction to the Strand7 finite element analysis system, 3rd ed., 2010, Strand7 Pty Limited, Sydney, Australia

Grigorian CE, Yang TS, Popov EP (1993) Slotted bolted connection energy dissipators. Earthq Spectr 9(3):491-504

Guerrero H, Ji T, Escobar JA, Teran-Gilmore A (2018) Effects of buckling-restrained braces on reinforced concrete precast models subjected to shaking table excitation. Eng Struct 163:294-310

Kanyilmaz A, Degée H, Castiglioni CA (2018) An adjusted design approach for concentrically braced frames in low-to-moderate seismicity areas. Bull Earthq Eng 16:4159-4189

Kanyilmaz A (2017a) Secondary frame action in concentrically braced frames designed for moderate seismicity: a full scale experimental study. Bull Earthq Eng 15:2101-2127

Kanyilmaz A (2017b) Role of compression diagonals in concentrically braced frames in moderate seismicity: a full scale experimental study. J Constr Steel Res 133:1-18

Kanyilmaz A (2018) Moderate ductility of the bracing joints with preloaded bolts. Bull Earthq Eng 16:503-527

Kelly JM, Skinner R, Heine A (1972) Mechanisms of energy absorption in special devices for use in earthquake resistant structures. Bull NZ Soc Earthq Eng 5(3):63-88

Kim J, Choi H, Min KW (2003) Performance-based design of added viscous dampers using capacity spectrum method. J Earthq Eng 7(1):1-24

Magliulo G, Ercolino M, Petrone C, Coppola O, Manfredi G (2014) Emilia earthquake: the sesmic performance of precast RC buildings. Earthq Spectra 30(2):891-912

Martinelli L, Mulas MG, Perotti F (1996) The seismic response of concentrically braced moment-resisting steel frames. Earthq Eng Struct Dynam 25(11):1275-1299

Martinelli L, Mulas MG, Perotti F (1998) The seismic behaviour of steel moment-resisting frames with stiffening braces. Eng Struct 20(12):1045-1062

Martinelli L, Mulas MG (2010) An innovative passive control technique for industrial precast frames. Eng Struct 32(4):1123-1132

Martìnez-Rueda JE (2002) On the evolution of energy dissipation devices for seismic design. Earthq Spectra 18(2):309-346

Monir HS (2013) Flexible blast resistant steel structures by using unidirectional passive dampers. J Constr Steel Res 90:98-107

Mousavi SA, Mehdi ZS, Saatcioglu M (2015) Toward buckling free tension-only braces using slack free connections. J Constr Steel Res 115:329-345

Mualla IH, Belev B (2002) Performance of steel frames with a new friction damper device under earthquake excitation. Eng Struct 24:365-371

Pall AS, Marsh C (1982) Seismic response of friction damped braced frames. ASCE J Struct Eng 108(6):1313-1323

Perotti F, De Amici A, Venturini P (1996) Numerical analysis and design implications of the seismic behaviour of one-storey steel bracing systems. Eng Struct 18(2):162-178

Perotti F, Scarlassara GP (1991) Concentrically braced steel frames under seismic actions: non-linear behaviour and design coefficients. Earthq Eng Struct Dyn 20(5):409-427

Pollini AV, Buratti N, Mazzotti C (2018) Experimental and numerical behaviour of dissipative devices based on carbon-wrapped steel tubes for the retrofitting of existing precast RC structures. Earthq Eng Struct Dynam 47(5):1270-1290

Popov EG, Takanashi K, Roeder CW (1976) Structural steel bracing systems: behavior under cyclic loading. Earthquake Engineering Research Center, College of Engineering, University of Berkeley, California (USA)

Savoia M, Buratti N, Vincenzi L (2017) Damage and collapses in industrial precast buildings after the 2012 Emilia earthquake. Eng Struct 137:162-180

Skinner RI, Kelly JM, Heine AJ (1974) Hysteretic dampers for earthquake-resistant structures. Earthq Eng Struct Dynam 3(3):287-296

Soong TT, Dargush GF (1997) Passive energy dissipation systems in structural engineering. Wiley, New York

Sorace S, Terenzi G (2017) Existing prefab R/C industrial buildings: seismic assessment and supplemental damping-based retrofit. Soil Dyn Earthq Eng 94:193-203 
Symans MD, Charney FA, Whittaker AS, Constantinou MC, Kircher CA, Johnson MW, McNamara RJ (2008) Energy dissipation systems for seismic applications: current practice and recent developments. ASCE J Struct Eng 134(1):3-21

Takeda T, Sozen MA, Nielsen NN (1970) Reinforced concrete response to simulated earthquakes. ASCE J Struct Div 96(12):2557-2573

Tamai H, Takamatsu T (2005) Cyclic loading tests on a non-compression brace considering performancebased seismic design. J Constr Steel Res 61(9):1301-1317

Toniolo G, Colombo A (2012) Precast concrete structures: the lessons learned from the L'Aquila earthquake. Struct Concr 13(2):73-83

Tremblay R (2002) Inelastic seismic response of steel bracing members. J Constr Steel Res 58:665-701

Tremblay R, Bolduc P, Neville R, DeVall R (2006) Seismic testing and performance of buckling-restrained bracing systems. Can J Civ Eng 33(2):183-198

Valente M (2013) Seismic protection of R/C structures by a new dissipative bracing system. Proc Eng 54:785-794

Publisher's Note Springer Nature remains neutral with regard to jurisdictional claims in published maps and institutional affiliations.

\section{Authors and Affiliations}

\section{Bruno Dal Lago ${ }^{1}$ (D) Muhammad Naveed $^{2} \cdot$ Marco Lamperti Tornaghi $^{3}$}

1 Department of Theoretical and Applied Sciences, Università Degli Studi Dell'Insubria, 21100 Varese, Italy

2 Department of Civil Engineering, GIK Institute of Engineering Sciences and Technology, Swabi 23640, Khyber Pakhtunkhwa, Pakistan

3 Joint Research Centre, European Commission, via Enrico Fermi 2749, 21027 Ispra, Italy 